\title{
CContributions of Weakly Coupled Data Assimilation-Based Land Initialization to Interannual Predictability of Summer Climate over Europe
}

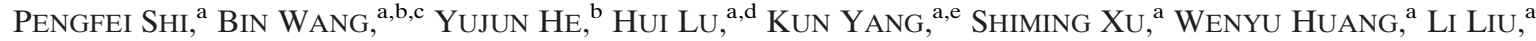 \\ JUANJUAN LiU, ${ }^{\mathrm{b}}$ LIJUAN Li, ${ }^{\mathrm{b}}$ AND YONG WANG ${ }^{\mathrm{a}}$ \\ a Ministry of Education Key Laboratory for Earth System Modeling, Department of Earth System Science, \\ Tsinghua University, Beijing, China \\ ${ }^{\mathrm{b}}$ State Key Laboratory of Numerical Modeling for Atmospheric Sciences and Geophysical Fluid Dynamics, \\ Institute of Atmospheric Physics, Chinese Academy of Sciences, Beijing, China \\ ${ }^{\mathrm{c}}$ College of Ocean Sciences, University of Chinese Academy of Sciences, Beijing, China \\ ${ }^{\mathrm{d}}$ Ministry of Education Field Observation and Research Station for Ecology of East Asian Migratory Birds and Their Habitats, \\ Beijing, China \\ ${ }^{\mathrm{e}}$ Center for Excellence in Tibetan Plateau Earth Sciences, Chinese Academy of Sciences, Beijing, China
}

(Manuscript received 2 July 2020, in final form 14 October 2021)

\begin{abstract}
The land surface is a potential source of climate predictability over the Northern Hemisphere midlatitudes but has received less attention than sea surface temperature in this regard. This study quantified the degree to which realistic land initialization contributes to interannual climate predictability over Europe based on a coupled climate system model named FGOALS-g2. The potential predictability provided by the initialization, which incorporates the soil moisture and soil temperature of a land surface reanalysis product into the coupled model with a dimension-reduced projection four-dimensional variational data assimilation (DRP-4DVar)-based weakly coupled data assimilation (WCDA) system, was analyzed first. The effective predictability (i.e., prediction skill) of the hindcasts by FGOALS-g2 with realistic and well-balanced initial conditions from the initialization were then evaluated. Results show an enhanced interannual prediction skill for summer surface air temperature and precipitation in the hindcast over Europe, demonstrating the potential benefit from realistic land initialization. This study highlights the significant contributions of land surface to interannual predictability of summer climate over Europe.
\end{abstract}

KEYWORDS: Climate prediction; Data assimilation; Europe; Summer/warm season; Interannual variability

\section{Introduction}

Large swings in climate on the interannual time scale can potentially cause more climate extremes, such as floods, droughts, and heat waves. In countries with large populations, even a moderate increase in climate variability can have profound social and economic impacts. Understanding the sources and improving the prediction skill of interannual predictability are therefore important, not only for the people who live in these regions but also for the investigations and predictions of possible consequences for the global climate system (Seneviratne et al. 2006).

Interannual atmospheric variability is mainly associated with the interactions between the atmosphere and other major components in the climate system, such as the ocean and land. The development of operational climate prediction centers has been motivated by the increasing ability to simulate and predict sea surface temperature (SST) anomalies (Conil et al. 2007; Saha et al. 2014). Nevertheless, the ocean has a limited impact on continental midlatitude areas during summer (Dirmeyer et al. 2003). Some studies found little evidence of significant prediction skill for precipitation and temperature over the midlatitudinal land areas, even in

¿Denotes content that is immediately available upon publication as open access.

Corresponding author: Bin Wang, wab@lasg.iap.ac.cn; Yujun He, heyujun@mail.iap.ac.cn the presence of skillful SST predictions (Wang et al. 2009). In these areas, the impact of the land surface is thus more important (Koster et al. 2010). By controlling the heat and water budget of the planetary boundary layer, the land surface plays a critical role in the climate system. Thus, with the capacity to retain anomalous signals over a long period, the land surface has been recognized as an important source of climate predictability at seasonal to interannual time scales (Liu 2003).

Realistic land initialization can contribute to hydroclimate prediction, as demonstrated by many studies (Draper et al. 2012; Orsolini et al. 2013; Sahoo et al. 2013). To obtain accurate initial land conditions, the most widely used approach is assimilating satellite-based land observations into land surface models in offline mode (Dirmeyer 2005). However, most of the previous studies focused on an offline assimilation scheme using a land surface model. Little attention has been paid to an online land data assimilation (LDA) scheme using a coupled land-atmosphere model or a coupled climate system model. Meanwhile, many LDA studies have mainly focused on time scales from days to months (Lin et al. 2016; Seo et al. 2019). Several previous studies have used atmospheric general circulation model (AGCM) simulations to investigate the contribution of land-atmosphere feedbacks to interannual climate variability on the global scale (Koster et al. 2010; Zhang et al. 2011). However, the degree to which LDA can advance interannual climate prediction with a coupled climate model is still largely unexplored. Most climate models do not 
realistically initialize the land surface, although its importance has been recognized for over a decade in the community (Santanello et al. 2016; Ardilouze et al. 2019).

The initialization strategies for the land surface in the coupled models are still at an exploratory stage, including coupled data assimilation (CDA) and uncoupled methods. Many efforts have been made to initialize the land surface in the coupled models through directly using the land surface conditions from the reanalysis data such as ERA-Land (Prodhomme et al. 2016; Ardilouze et al. 2017). The uncoupled method is timesaving and easily implemented, but this method initializes a model with data derived from another model and could ultimately degrade the prediction skill due to inconsistencies at the land-atmosphere interface (Ardilouze et al. 2017). A better initialization would imply to perform a CDA for climate predictions at seasonal, annual and decadal scales. The CDA method incorporates observations to one or several components of the coupled model during a coupled integration of several decades (i.e., assimilation cycle) (He et al. 2020a). The CDA method is superior to the uncoupled approach because a long-term assimilation cycle is conducted under the framework of the coupled model, and therefore the initial conditions (ICs) prepared by the CDA are more coordinated with the coupled model (Balmaseda et al. 2009; Liu et al. 2017). A small number of the coupled models apply different data assimilation techniques to initialize the land surface, such as a simple nudging approach $(\mathrm{Hu}$ et al. 2009), the three-dimensional variational data assimilation (3DVar) (Lin et al. 2017) or ensemble Kalman filter (EnKF) (Lin et al. 2016). These methods are more coherent with the coupled model than the uncoupled initialization methods. Four-dimensional variational data assimilation (4DVar) considers the model constraint and provides a good fit to observations along the model trajectory in the assimilation window (He et al. 2020b). Thus, the ICs obtained from 4DVar tend to have better consistency with the model than simple assimilation methods like nudging and 3DVar (Sugiura et al. 2008). However, very few models attempt to apply the 4DVar-based initialization method (Liu et al. 2017), probably due to the large computing expense of the adjoint model and the difficulty in building the adjoint model of a coupled model or its components.

This study aims to investigate the impact of an advanced online LDA scheme on potential predictability and prediction skill on interannual climate variability using a coupled climate system model with a 4DEnVar assimilation method. For this purpose, a weakly coupled data assimilation (WCDA) system was developed to constrain the land state variables of the coupled model by assimilating a land reanalysis product. This WCDA system is expected to generate accurate land initial conditions (LICs) and well-balanced initial states of the coupled multisphere system through the inclusion of multisphere interactions in the LDA. Hindcast experiments are designed to investigate the impact of realistic land initialization on the interannual prediction skill. Sensitivity experiments are used to demonstrate the important role of well-balanced ICs from the WCDA system.

Section 2 describes the coupled climate system model and the experimental design. Section 3 introduces the methods to quantify the contribution of land initialization to interannual climate variability and is followed by the analysis and evaluation of potential and effective predictabilities in section 4 . Finally, section 5 presents the summary and discussion.

\section{Model, data, and experimental design}

\section{a. Model description}

The model used in this study is a fully coupled climate system model, namely, the Flexible Global Ocean-Atmosphere-Land System Model gridpoint version 2 (FGOALS-g2), jointly developed by the State Key Laboratory of Numerical Modeling for Atmospheric Sciences and Geophysical Fluid Dynamics (LASG), Institute of Atmospheric Physics (IAP), Chinese Academy of Science (CAS), and the Department for Earth System Science (DESS), Tsinghua University (Li et al. 2013a). FGOALS-g2 couples the Gridpoint Atmospheric Model version 2 (GAMIL2) (Li et al. 2013b), LASG/IAP Climate Ocean Model version 2 (LICOM2) (Liu et al. 2012), Community Land Model version 3 (CLM3) (Oleson et al. 2010) and the improved version of Community Ice Code version 4 by LASG (CICE4LASG) (Wang 2009) through the CPL6 coupler (Craig et al. 2005) that computes and exchanges the heat flux, momentum, and freshwater flux among the aforesaid component models. The performance of the FGOALS-g2 model was systematically evaluated (Li et al. 2013b).

\section{b. Datasets}

Three types of reanalysis data are used as follows: 1) Monthly soil moisture and soil temperature data produced by the Global Land Data Assimilation System (GLDAS) for initialization. The GLDAS products combine satellite data and land surface models to estimate global distributions of land surface states (Rodell et al. 2004). The GLDAS datasets have been provided since January 1979 and are available for download from the Giovanni online data system maintained by the National Aeronautics and Space Administration Goddard Earth Sciences Data and Information Services Center (Mei et al. 2013; Zhang et al. 2008). The GLDAS data used in this study are from the CLM model, which is the same land surface model from FGOALS-g2. 2) Global Precipitation Climatology Project (GPCP) version 2 Monthly Precipitation Analysis data for evaluation (Adler et al. 2003). This dataset is derived from precipitation estimates based on low-orbit satellite microwave data, geosynchronous-orbit satellite infrared data, and surface rain gauge observations. 3) The NCEP Climate Forecast System Reanalysis (CFSR) data for evaluation (Saha et al. 2010), including surface air temperature (T2m), sensible heat flux, and latent heat flux. Most available in situ and satellite observations are included in the CFSR to provide the best estimate of Earth's climate state for community climate research.

\section{c. Assimilation scheme for initialization}

Data assimilation (DA) techniques have been employed as an effective strategy to combine the strengths of both modeling and observations to generate superior estimates by appropriately weighting their respective sources of errors (Reichle 
TABLE 1. Lists of numerical experiments.

\begin{tabular}{lc}
\hline \hline Numerical experiments & Description \\
\hline CTRL & A free coupled run to provide a reference for comparisons from 1980 to 2015 \\
ASSIM & An initialization run to provide realistic initial conditions for the hindcasts from 1980 to 2015 \\
HCST & Hindcasts to investigate the impact of the initial conditions from ASSIM on model prediction skills \\
& every five years from 1981 to 2006 with three ensemble members \\
SNS & Sensitivity experiments to demonstrate the importance of well-balanced initial conditions from \\
& ASSIM every five years from 1981 to 2006 with three ensemble members \\
\hline
\end{tabular}

et al. 2008). The assimilation system used here is based on the dimension-reduced projection four-dimensional variational data assimilation (DRP-4DVar), which is an economical approach of implementing 4DVar by projecting model variables onto a low-dimensional sample space (Wang et al. 2010; Liu et al. 2011). The DRP-4DVar method directly obtains an optimal solution in the reduced space by fitting observations with historical model prediction samples to form consistent initial states for forecasts. Notably, this assimilation scheme was adopted in establishing the WCDA to constrain the ocean component of the same coupled model with an ocean reanalysis product (He et al. 2017, 2020a,b).

The DRP-4DVar method (Wang et al. 2010) produces an analysis in a low-dimension sample space first:

$$
\boldsymbol{\alpha}_{a}=\left(\mathbf{B}_{\alpha}^{-1}+\mathbf{P}_{y}^{\mathrm{T}} \mathbf{P}_{y}\right)^{-1} \mathbf{P}_{y}^{\mathrm{T}} \tilde{\mathbf{y}}_{\mathrm{obs}}^{\prime}
$$

by minimizing a 4DVar cost function projected into this sample space, i.e.,

$$
\tilde{J}\left(\boldsymbol{\alpha}_{a}\right)=\min _{\alpha \in E_{m}} \tilde{J}(\boldsymbol{\alpha})
$$

where

$$
\tilde{J}(\boldsymbol{\alpha})=\frac{1}{2} \boldsymbol{\alpha}^{\mathrm{T}} \mathbf{B}_{\boldsymbol{\alpha}}^{-1} \boldsymbol{\alpha}+\frac{1}{2}\left(\mathbf{P}_{y} \boldsymbol{\alpha}-\tilde{\mathbf{y}}_{\mathrm{obs}}^{\prime}\right)^{\mathrm{T}}\left(\mathbf{P}_{y} \boldsymbol{\alpha}-\tilde{\mathbf{y}}_{\mathrm{obs}}^{\prime}\right)
$$

Then this analysis is projected back to the model space:

$$
\mathbf{x}_{a}=\mathbf{x}_{b}+\mathbf{x}_{a}^{\prime}=\mathbf{x}_{b}+\mathbf{P}_{x} \boldsymbol{\alpha}_{a}
$$

The subscripts $a, b$, and obs denote the analysis, background and observation, respectively; the superscript $\mathrm{T}$ denotes matrix transpose; $\mathbf{x}$ and $\mathbf{x}^{\prime}$ are the column vector forms of ICs and their increments or perturbations, respectively; $\mathbf{P}_{x}$ is the projection matrix consisting of $m$ IC perturbations; $\boldsymbol{\alpha}$ is an $m$-dimension column vector whose components are the weight coefficients; $\mathbf{P}_{y}$ is the projection matrix composed of the simulation of the weighted observation increment; $\tilde{\mathbf{y}}_{\text {obs }}^{\prime}$ denotes the weighted observational innovation; $\mathbf{B}_{\alpha}$ means the background error covariance matrix in the sample space. To remove the false remote correlations in the background error covariance due to the use of the limited number of ensemble samples, the economical localization procedure is used when the analysis in the sample space is projected back to the model space (Wang et al. 2018).

In this study, DRP-4DVar is used to produce optimal analysis of initial conditions of the coupled model (i.e., FGOALS-g2) with 1-month assimilation windows in a 36-yr coupled assimilation cycle from 1980 to 2015, which best fits the monthly mean soil moisture and temperature from the GLDAS project with all 10 soil layers along the trajectory of the coupled model. Within each assimilation window, three steps are executed to complete each assimilation in the initialization: 1) the coupled model is first run for one month, so that its land surface component produces the simulation of monthly mean soil temperature and soil moisture; 2) at the end of the assimilation window, the observational innovation is calculated based on the differences of the monthly mean soil temperature and soil moisture between the GLDAS and the model simulation, and then this innovation is fed back to the beginning of the window to produce an optimal estimation of IC using the DRP-4DVar approach; and, finally, 3) from the beginning of the window, the coupled model is rerun for one month using the assimilation analysis as the IC to produce the background for the next assimilation. Currently, the state variables of background in the assimilation only include the basic variables of the land component (i.e., soil moisture, soil temperature, and snow depth). Meanwhile, the 1-month free coupled integration after the assimilation analysis at the beginning of each month propagates the information of GLDAS reanalysis into other components (e.g., atmosphere and ocean) at the end of the month and thus produces well-balanced initial states of these components for the next assimilation.

\section{d. Numerical experiments}

Here, the WCDA system constrained by land observations (described in detail in section 2c) is used to investigate the contributions of land surface states to interannual predictability of summer climate over Europe. Four sets of numerical experiments are designed to investigate the impacts of LDA and land initialization on summer climate predictability on the interannual time scale. The descriptions of the numerical experiments are listed in Table 1.

The control simulation (CTRL) is a continuous free coupled run for 36 years covering 1980-2015, driven by external forcing only. This simulation provides a reference for evaluating the performance of the WCDA system and investigating the impact of the initial state on prediction skills. The second experiment (ASSIM) consists of a 36-yr assimilation cycle from 1980 to 2015 that assimilates the monthly mean soil moisture and temperature from the GLDAS project into the land component of FGOALS-g2 with 1-month assimilation windows. Within each assimilation time window, the coupled model runs freely except that the GLDAS data are assimilated into the land state variables at the beginning of the assimilation 
window. Although other components (e.g., atmosphere and ocean) of the coupled model are not assimilated, freely coupled integrations inside the 1-month assimilation window can transfer the observed land information from the land component to other components through multisphere interactions (Shi et al. 2021). This free coupled integration not only prepares realistic ICs for the land component, but also provides well-balanced ICs for other components. Comparing between ASSIM and CTRL allows the impacts of LDA in the coupled model to be evaluated. In contrast with offline LDA, this WCDA system retains the land-atmosphere interaction and atmospheric feedback during the free coupled integration in the 1-month-long assimilation window and thus generates well-balanced and coherent coupled land-atmosphere ICs for HCSTs. Although the control variables of data assimilation do not include any variables of other components (e.g., atmosphere and ocean) of the coupled model, the observed land information can influence the states of these components through model coupling (Shi et al. 2021). This coupled model framework with land data assimilation is referred to as a WCDA system.

The third experiment features HCST experiments initialized by ASSIM. HCST experiments are performed to evaluate the impact of realistic ICs on model prediction skills. In HCST, realistic and well-balanced ICs for all model components of FGOALS-g2 are provided by ASSIM to conduct each hindcast. HCST includes six sets of hindcasts, which are conducted every five years from 1981 to 2006 with three ensemble members that respectively start from 1 January of the above beginning years and on 1 September and 1 November of the previous years of the beginning years. Six sets of 10 -yr-long hindcast experiments (HCST) are conducted using FGOALSg2, which consist of three ensemble members starting from 1 January (member 1) from 1981 to 2006, 1 November (member 2) and 1 September (member 3) from 1980 to 2005 with a 5-yr interval. The time series combining the six sets of HCST for years $1-5$ are chosen for the coming evaluations and discussions with monthly mean outputs in each month or JuneAugust (JJA) averaged outputs in each year, because these time series have higher anomaly correlation coefficients (ACCs) with the observation than other combined time series (e.g., those for years 2-6, years 3-7) in general. The first five years of each set of ensemble mean hindcast are combined into continuous time series from 1981 to 2010 for the following analyses and evaluations.

Last, six hindcast sensitivity experiments are conducted using different combinations of ICs for the atmosphere, land, and ocean of the coupled model. The hindcast sensitivity experiments are designed to demonstrate the importance of well-balanced multicomponent ICs from this WCDA system. Sensitivity experiments (SNS) systematically replace the well-balanced atmosphere, land, and ocean states from ASSIM with those from offline LDA or CTRL as ICs in hindcast experiments one at a time. In SNS1, the land ICs are computed from an offline land surface model (CLM3) and are then used in the coupled model simulation. The atmosphere and ocean ICs are taken from CTRL, and the land ICs are taken from an offline initialization using the FGOALS-g2 land component model with the same LDA system as used in ASSIM. The other five sensitivity experiments replace the well-balanced atmosphere, land, and ocean states from ASSIM with those from CTRL. For SNS2, the atmosphere and land ICs are taken from ASSIM, and the ocean ICs are from CTRL. In SNS3, the atmosphere and land ICs are from CTRL while the ocean ICs are from ASSIM. For SNS4, the atmosphere ICs are taken from CTRL, and the land and ocean ICs are from ASSIM. In SNS5, the atmosphere ICs are from ASSIM while the land and ocean ICs are from CTRL. For SNS6, the atmosphere and ocean ICs are taken from CTRL, and the land ICs are from ASSIM. All these experiments have three ensemble members and are performed in the same way as HCST.

\section{Methods}

In this study, three available indices are adopted, and a new index is defined to determine where and when the land surface state has a dominant impact on the atmosphere and then objectively quantify the contribution of the land surface state to the interannual climate variability. Three available indices include the $K$ index (Kanae et al. 2005), sensitivity index (Dirmeyer 2011), and potential predictability (Conil et al. 2007). The $K$ index identifies whether climate variability at a location is mainly regulated by water or energy. Determining whether a location is mainly regulated by water could help to determine if land surface water actively controls the surface fluxes. The sensitivity index quantifies the response of a climate variable to a land variable. The sensitivity index reflects the potential of strong land-atmosphere feedback. However, this sensitivity index does not diagnose how strongly land surface could affect the near-surface atmospheric state. The potential predictability index isolates the observed variability in ASSIM from the simulated variability from the used model and identifies the performance of this initialization in incorporating observed variability with the variance contribution ratio. The potential predictability quantifies the ratio of the observed variability over the total variability. It can be understood as a measure of the coherency of the observed signal in ASSIM. To further quantify the role of realistic land initialization in improving climate prediction, a new index is proposed here to estimate effective predictability with a reduction ratio of the error variance. The effective predictability or prediction skill is evaluated using HCSTs computed against the available observations (Douville 2010). The objective of effective predictability is to quantitatively assess the contributions of realistic land initialization to interannual climate predictability in HCST. The descriptions of these indices are listed in Table 2.

a. K index

Determining whether a location is "water limited" or "energy limited" helps to decide whether land surface state information at that location could benefit climate predictions. 
TABLE 2. Lists of different indices to quantify the contribution of land surface to interannual climate predictability.

\begin{tabular}{|c|c|c|c|}
\hline Name & Purpose & Description & Variables used \\
\hline$K$ index & $\begin{array}{l}\text { To identify whether the } \\
\text { location is water or energy } \\
\text { limited }\end{array}$ & $\begin{array}{l}\text { Value ranges from }-1 \text { to } 1 \\
\text { Positive value suggests energy } \\
\text { limited; negative value suggests } \\
\text { water limited }\end{array}$ & Sensible heat flux, latent heat flux \\
\hline Sensitivity index & $\begin{array}{l}\text { To quantify the response of } \\
\text { the atmospheric variable to } \\
\text { the land variable }\end{array}$ & $\begin{array}{l}\text { Value ranges from }-1 \text { to } 1 \\
\text { High value indicates high } \\
\text { sensitivity; low value indicates } \\
\text { low sensitivity }\end{array}$ & $\begin{array}{l}\text { Surface air temperature, } \\
\text { precipitation, soil moisture, soil } \\
\text { temperature }\end{array}$ \\
\hline Potential predictability & $\begin{array}{l}\text { To isolate the observed } \\
\text { variability of ASSIM from } \\
\text { the simulated variability } \\
\text { from model }\end{array}$ & $\begin{array}{l}\text { High value implies that potential } \\
\text { predictability is strong; low value } \\
\text { implies that potential } \\
\text { predictability is weak }\end{array}$ & $\begin{array}{l}\text { Surface air temperature, } \\
\text { precipitation, evaporation, latent } \\
\text { heat flux, sensible heat flux, soil } \\
\text { moisture, soil temperature }\end{array}$ \\
\hline Effective predictability & $\begin{array}{l}\text { To evaluate the prediction } \\
\text { skill of HCST against the } \\
\text { available observations in } \\
\text { terms of the spatial } \\
\text { distribution and time } \\
\text { evolution }\end{array}$ & $\begin{array}{l}\text { Positive value suggests poor } \\
\text { hindcast skill; negative value } \\
\text { suggests improved hindcast skill } \\
\text { From the EOF analysis, high } \\
\text { correlation with observation } \\
\text { suggests improved hindcast skill; } \\
\text { low correlation with observation } \\
\text { suggests poor hindcast skill }\end{array}$ & $\begin{array}{l}\text { Surface air temperature, } \\
\text { precipitation }\end{array}$ \\
\hline
\end{tabular}

Here, we followed the unique index ( $K$ index) proposed by Kanae et al. (2005), i.e., the correlation coefficient between latent and sensible heat fluxes, to identify whether a location is mainly regulated by "water" or "radiation."

The $K$ index is defined as

$$
K=\operatorname{COR}(\mathrm{LHF}, \mathrm{SHF})
$$

Here, COR(LHF, SHF) is the correlation coefficient between the time series of latent heat flux (LHF) and sensible heat flux (SHF) from 1985 to 2008. A negative $K$ index suggests that "water" regulates the variability in the surface fluxes. Namely, if the soil is wetter than normal, latent heat flux will be above normal, and the sensible heat flux will be below normal. Land surface conditions actively control the surface fluxes and therefore the atmosphere. In contrast, a positive $K$ index implies that "radiation" regulates the variability in surface fluxes. When the input radiation to the surface is below normal, both the latent and sensible heat fluxes will be below normal, presumably because of cloud cover anomalies. Land surface water has little influence in this case, and the atmosphere plays a leading role.

\section{b. Sensitivity index}

The sensitivity index was initially used by Dirmeyer (2011) and recently used in other studies (Wei and Dirmeyer 2012; Liu et al. 2013). To quantify the characteristic impact that the variations in a land variable $\omega$ (e.g., soil moisture or soil temperature) may have on an atmospheric variable $\varphi$ (e.g., precipitation or temperature), an index to measure the strength of the sensitivity of this atmospheric variable $\varphi$ to land variable $\omega$ is calculated as follows:

$$
I_{\varphi}=\frac{\partial \varphi}{\partial \omega} \sigma(\omega)
$$

where $\partial \varphi / \partial \omega$ is the derivative (sensitivity) of $\varphi$ with respect to $\omega$ and $\sigma(\omega)$ is the standard deviation (characteristic variability) of $\omega$. The sensitivity index takes into account not only the response of $\varphi$ to $\omega$ but also the potential for the fluctuations in $\omega$ to result in variations in $\varphi$. The $\partial \varphi / \partial \omega$ describes the slope of linear regression of precipitation (or temperature) against soil moisture (or soil temperature), and $\sigma(\omega)$ measures the standard deviation of soil moisture (or soil temperature). Monthly atmospheric variable (e.g., precipitation or temperature) and land variable (e.g., soil moisture or soil temperature) data from FGOALS-g2 are used to calculate the sensitivity index. The land variables used to quantify the sensitivity strength of the atmosphere to the land in this study are the top 10-cm depth soil temperature and soil moisture. Other depths (e.g., 20 and $60 \mathrm{~cm}$ ) were tested, and the results were not qualitatively sensitive to the depth of soil chosen, as mentioned in Liu et al. (2013). The sensitivity index is calculated using monthly mean values across 24 years (1985-2008) for the summer season of JJA, including 72 months.

\section{c. Potential predictability index}

Using a one-way analysis of variance (ANOVA), which allows decomposition of the variance and thus enables the estimation of the variability forced by observations through the initialization (or DA) and of its ratio over the total variability, the potential predictability is estimated as

$$
\frac{\sigma_{v}^{2}(\mathrm{ASSIM})-\sigma_{v}^{2}(\mathrm{CTRL})}{\sigma_{v}^{2}(\mathrm{CTRL})},
$$

where $\sigma_{v}^{2}(\mathrm{CTRL})$ and $\sigma_{v}^{2}(\mathrm{ASSIM})$ represent the variance of a variable $v$ from CTRL and ASSIM, respectively. Details of this methodology can be found in many studies (Conil et al. 2007; Douville 2010).

\section{d. Effective predictability index}

To quantify the improvement in the initialized prediction of climate variability, an estimation of effective predictability is 
(a) Reanalysis

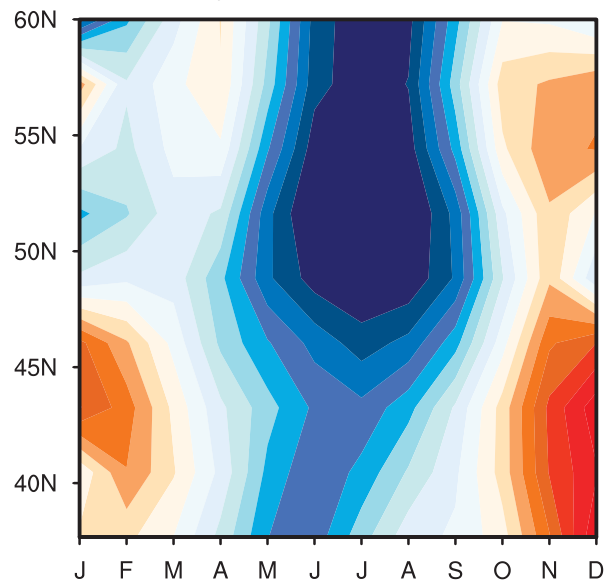

(c) CTRL

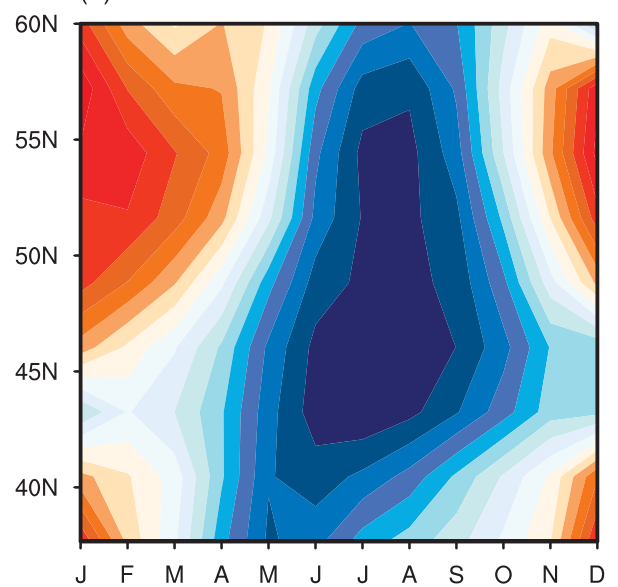

(b) ASSIM

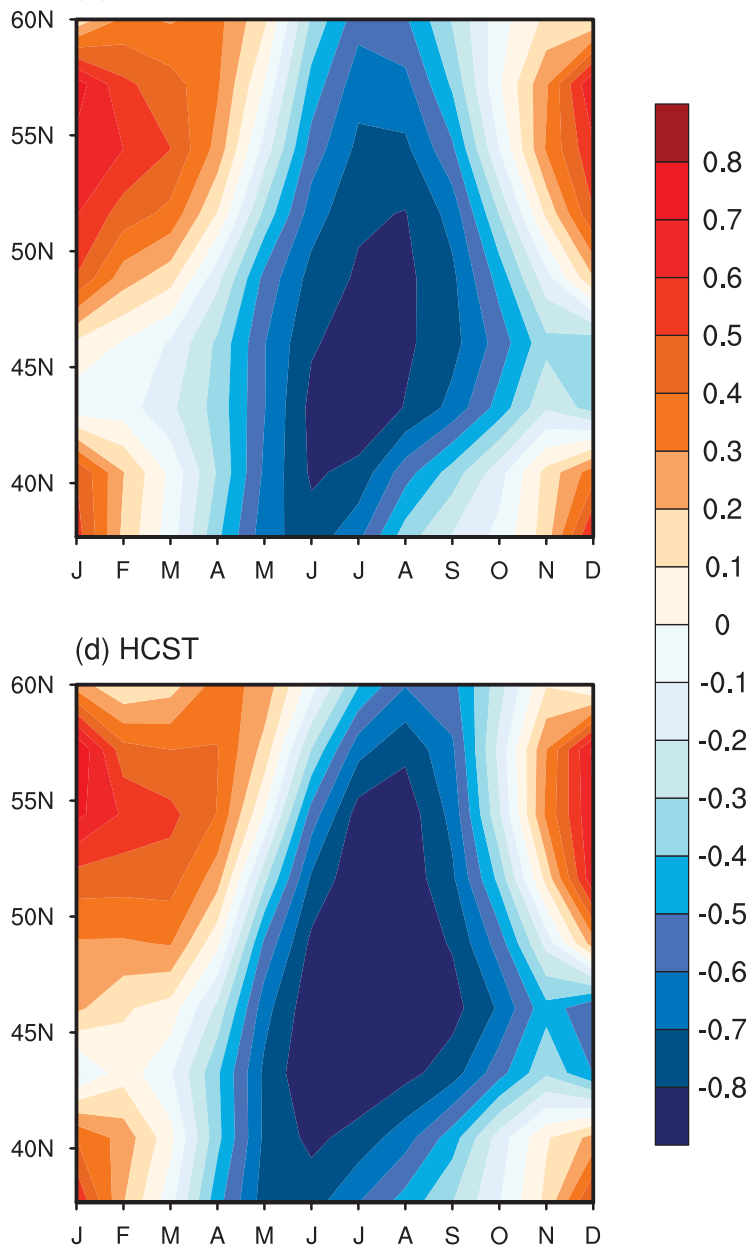

FIG. 1. Zonal mean annual cycle of the $K$ index for (a) the CFSR reanalysis data, (b) ASSIM, (c) CTRL, and (d) HCST, evaluated over Europe across $10^{\circ} \mathrm{W}-60^{\circ} \mathrm{E}$.

proposed; its definition is similar to the definition of the potential predictability index:

$$
\frac{\sigma_{v}^{2}(\mathrm{HCST}-\mathrm{OBS})-\sigma_{v}^{2}(\mathrm{CTRL}-\mathrm{OBS})}{\sigma_{v}^{2}(\mathrm{CTRL}-\mathrm{OBS})},
$$

where $\sigma_{v}^{2}(\mathrm{CTRL}-\mathrm{OBS})$ and $\sigma_{v}^{2}(\mathrm{HCST}-\mathrm{OBS})$ represent the error variance of a variable $v$ from CTRL and HCST, respectively. A negative value indicates a reduced root-mean-square error in the HCST due to the initialization.

The empirical orthogonal function (EOF) method, also known as principal component analysis (PCA), has been widely used in climate studies to analyze potential spatial modes (patterns) of variability and time variation. EOF analysis orders original spatiotemporal data into the matrix, based on which dominating "computational" modes are identified (Lian and Chen 2012). Mathematically, the spatial and temporal patterns of climate variability are represented by the EOF method to quantitatively assess the contributions of realistic land initialization to climate predictability from HCST.

\section{Results}

The $K$ index is used to confirm whether the location is water or energy limited. The sensitivity index quantifies the response of the atmospheric variable to the land variable. Then the potential predictability verifies the importance of land surface in the summer climate and reveals the potentially predictable variability throughout the annual cycle in ASSIM. Finally, effective predictability is used to quantify the contributions of realistic land initializations to summer climate predictability over Europe in HCST.

\section{a. Importance of land surface to European surface fluxes during summer}

Here, the annual cycle of the zonal mean $K$ index is used to determine where and when the location is water or energy limited. The index from the CFSR reanalysis data (Fig. 1a) indicates that the latitudes from $35^{\circ}$ to $60^{\circ} \mathrm{N}$ are "water limited" during the warm seasons from late spring to early autumn, according to the negative values of the $K$ index in 
(a) Reanalysis

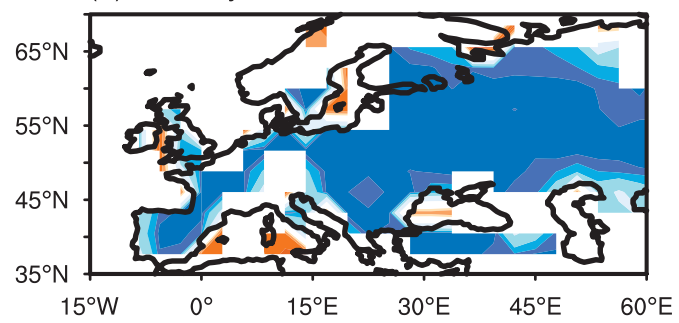

(c) CTRL

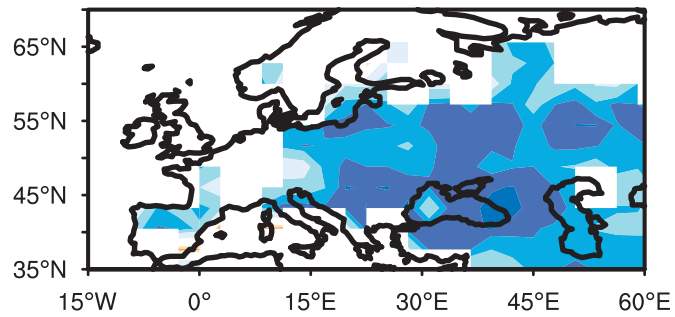

(b) ASSIM

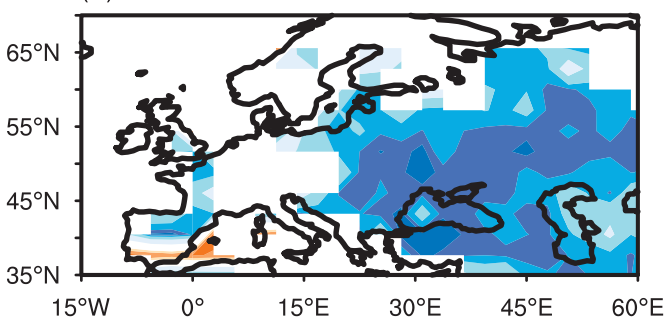

(d) HCST

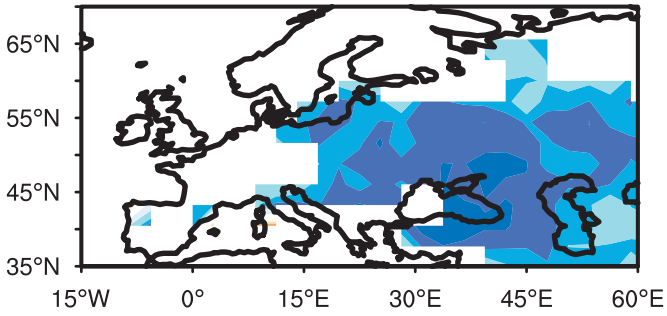

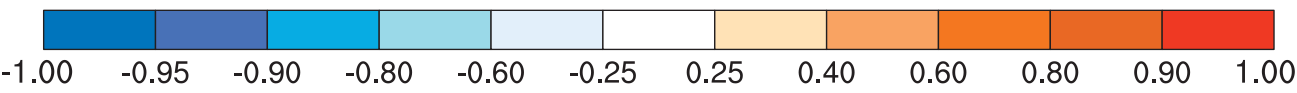

FIG. 2. Maps of the $K$ index for the June-August (JJA) period of 1985-2008 for (a) the CFSR reanalysis data,

(b) ASSIM, (c) CTRL, and (d) HCST. Shaded areas are statistically significant at the $95 \%$ confidence level.

this spatiotemporal range. The peak of the negative $K$-index value spatially extends from $45^{\circ}$ to $60^{\circ} \mathrm{N}$ during summer. On the other hand, from late autumn to early spring, the $K$ index mainly shows a positive signal, which indicates "energy limited" midlatitudinal land areas during the cold seasons. The climate model well represents the seasonal evolution of the $K$ index in the CFSR reanalysis data, regardless of whether the model is initialized or its land component is constrained by the GLDAS data, although southward location biases can be sighted in their peak centers of negative $K$ index (Figs. 1b-d). The annual cycle of the $K$ index is found to be robust across the data from the reanalysis data and model simulations. Land surface water actively influences the surface fluxes over the midlatitudinal land areas in the summer, which is consistent with other studies that showed that land surface water has large impacts on continental midlatitude areas during summer (Koster et al. 2011; Yoon and Leung 2015).

The spatial pattern of the $K$ index during summer is further analyzed over Europe at latitudes from $35^{\circ}$ to $70^{\circ} \mathrm{N}$. Figure 2 shows the $K$ index calculated for the summer period during 1985-2008. According to the CFSR reanalysis data, the European regions are characterized by a negative correlation (Fig. 2a), which suggests that such regions are "water limited." In this case, land surface water has significant impacts on regional climate. Shaded areas that are statistically significant at the 95\% confidence level are mainly located north of $45^{\circ} \mathrm{N}$ in the CFSR reanalysis data. From Figs. $2 \mathrm{~b}-\mathrm{d}$, shaded areas extend to $35^{\circ} \mathrm{N}$ in the ASSIM, CTRL, and HCST, which is closely related to the southward location biases found in Figs. 1b-d. However, the spatial patterns of strong negative signals for "water limited" diagnosed in all three simulations are fairly consistent with those in the CFSR reanalysis data, indicating that this index is robust in terms of its horizontal distribution across data from the reanalysis data and model simulations. Such locations with negative $K$ index imply that "water" regulates the variability of surface fluxes. Namely, if soil is wetter than normal, latent heat flux will be above normal and sensible heat flux will be below normal. The differences between the reanalysis data and model simulations are likely related to model deficiencies in both cloud physics and evapotranspiration processes as pointed out by Cheruy et al. (2014).

Both the annual cycle and spatial pattern of the $K$ index highlight the importance of the land surface state in the summer climate over Europe, where land conditions actively influence the surface fluxes and therefore the atmosphere. It is reasonable to suggest that water-regulating locations likely correspond to areas where the positive influence of realistic land conditions on climate predictability is apparent over Europe.

\section{b. Sensitivity of summer climate variability to land surface over Europe}

Based on the "water limited" characteristics over Europe in the summer season, the sensitivity of climate variability to the land surface state is further investigated. The sensitivity of summer climate to land surface states over Europe also supports the conclusion on the importance of land surface states in predictions of European summer climate. The reanalysis data show that the sensitivity of $\mathrm{T} 2 \mathrm{~m}$ to soil temperature is significantly positive over almost all of Europe (Fig. 3a), which is dominant in both strength and spatial coverage 

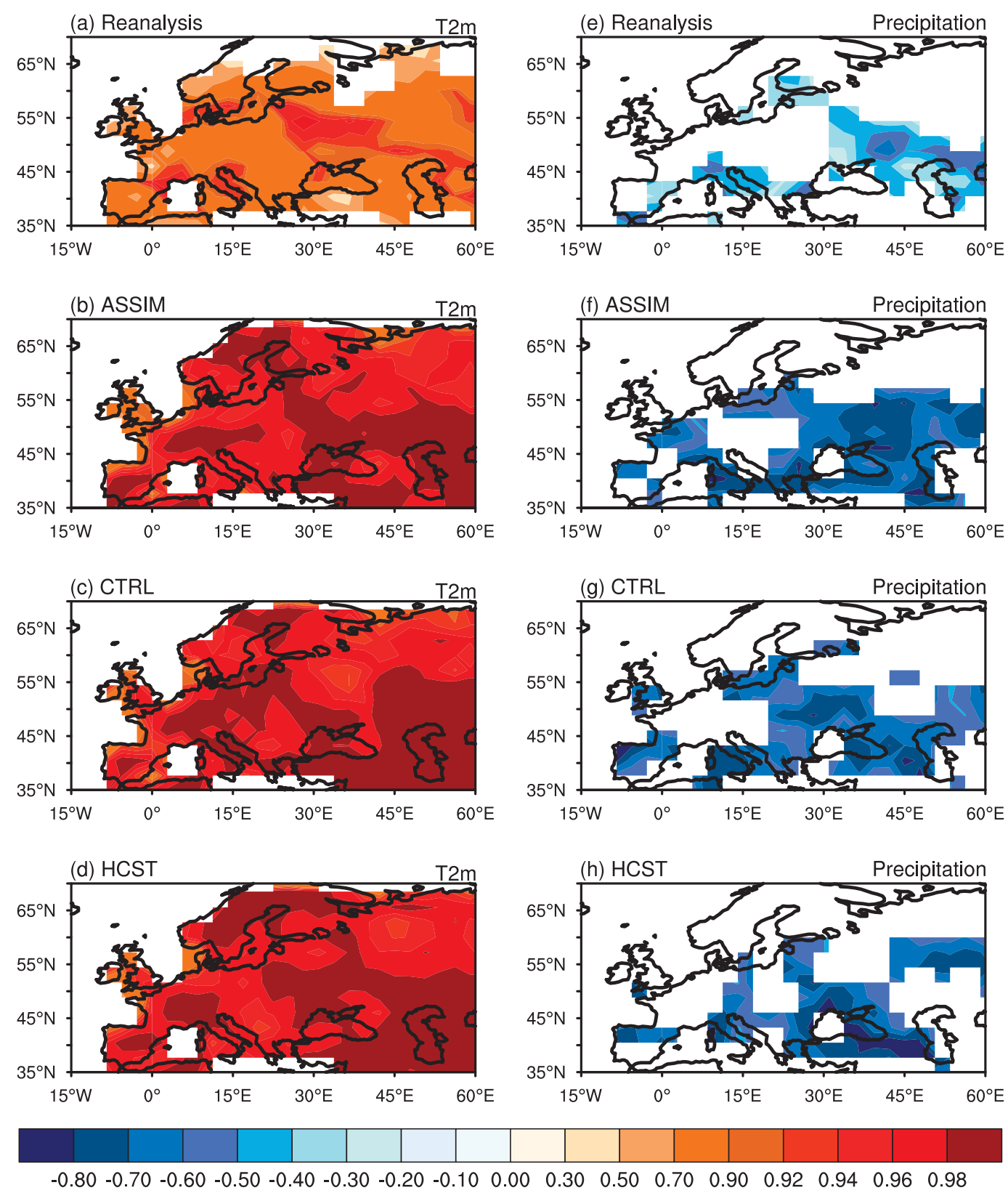

FIG. 3. The sensitivity of (left) surface air temperature and (right) precipitation to soil temperature for the JJA period of 1985-2008 for (a),(e) the reanalysis data, (b),(f) ASSIM, (c),(g) CTRL, and (d),(h) HCST. The shaded grid points are significant at the $95 \%$ confidence level.

compared to the sensitivity to soil moisture (Fig. 4a). The model captures these characteristics well in all three experiments (Figs. 3b-d and 4b-d). The dominant role of soil temperature in summer $\mathrm{T} 2 \mathrm{~m}$ over Europe in terms of sensitivity indicates that more realistic soil temperature from WCDA likely improves the $\mathrm{T} 2 \mathrm{~m}$ predictions.

Regarding summer precipitation over Europe, significantly positive (negative) sensitivity to soil moisture (temperature) can also be found in the central part of eastern Europe and the southern part of central Europe in the reanalysis data
(Figs. 3e and 4e). The model clearly underestimates the sensitivity of soil temperature on precipitation over the whole region (Figs. 3f-h), and overestimates the sensitivity of soil moisture on precipitation in central and western Europe (Figs. 4f-h). In comparison, summer precipitation over Europe is more sensitive to soil moisture than soil temperature. Similar to summer T2m predictions, summer precipitation predictions in some areas of Europe likely benefit from the assimilation of soil moisture and soil temperature from GLDAS due to the sensitivity of precipitation to land surface 

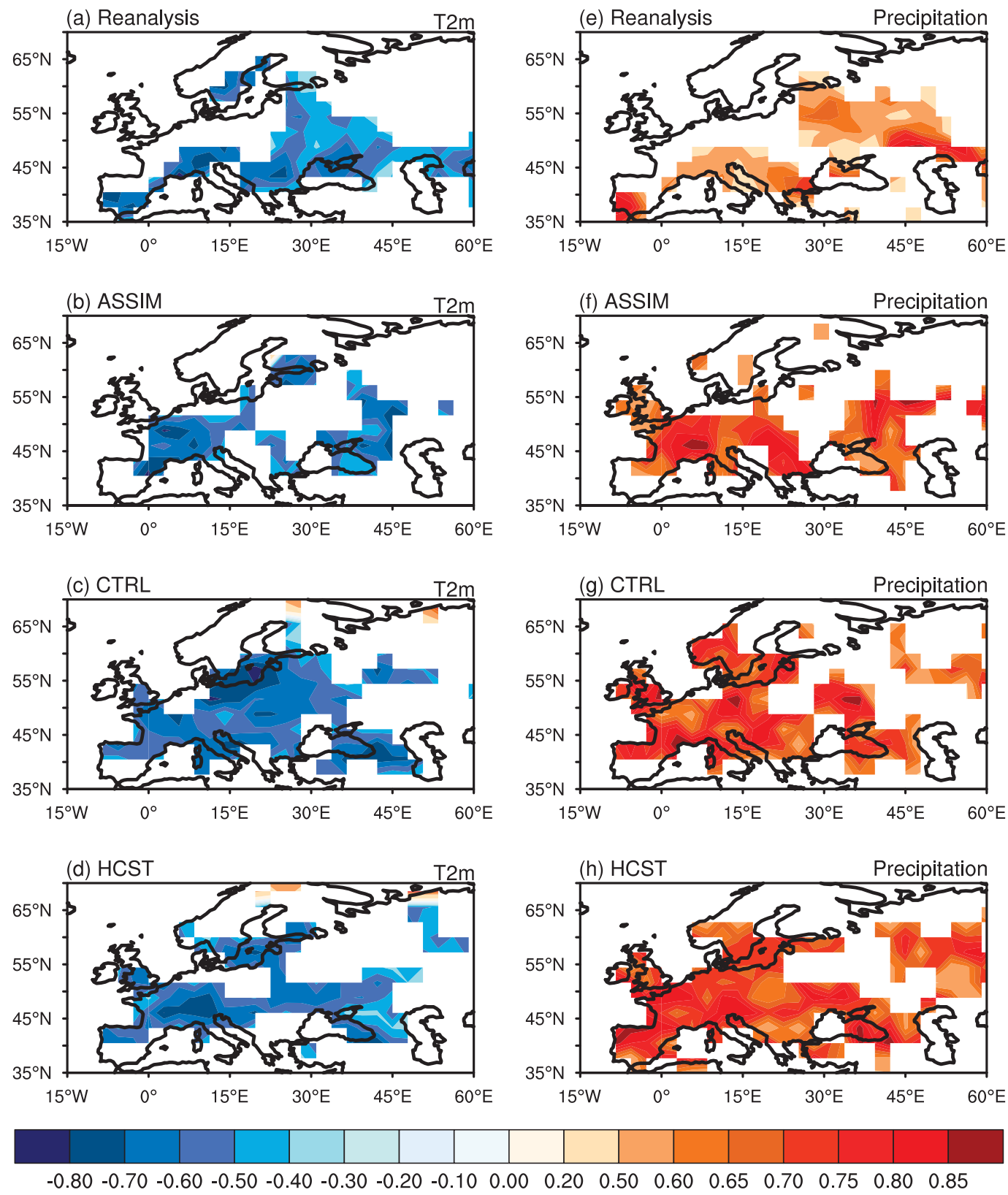

FIG. 4. The sensitivity of (left) surface air temperature and (right) precipitation to soil moisture for the JJA period of 1985-2008 for (a),(e) the reanalysis data, (b),(f) ASSIM, (c),(g) CTRL, and (d),(h) HCST. The shaded grid points are significant at the $95 \%$ confidence level.

states, although it is not as significant as that of $\mathrm{T} 2 \mathrm{~m}$ to soil temperature in terms of strength and spatial coverage.

\section{c. Potential predictability of summer climate over Europe}

The importance of the land surface state in summer climate over Europe can also be verified in the potential predictability from the WCDA system. Unlike an offline LDA that only provides potential predictability to land variables, the WCDA system propagates potential predictability from the land to the atmosphere through land-atmosphere coupling. The annual cycles of the zonal mean potential predictability of European climate according to Eq. (7) show a peak of predictability in the midlatitudes during summer for both the $\mathrm{T} 2 \mathrm{~m}$ and precipitation (Figs. 5a,b). The maximum predictability of $\mathrm{T} 2 \mathrm{~m}$ (precipitation) exceeds $60 \%(40 \%)$. The predictability of T2m exceeding $30 \%$ covers the latitudes from south of $35^{\circ}$ to $55^{\circ} \mathrm{N}$ and the time from middle May to early July, while that of precipitation spatially extends from south of 
(a) T2m

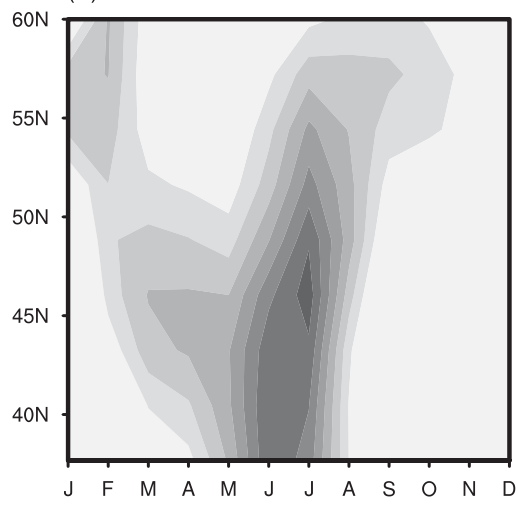

(d) Sensible Heat Flux

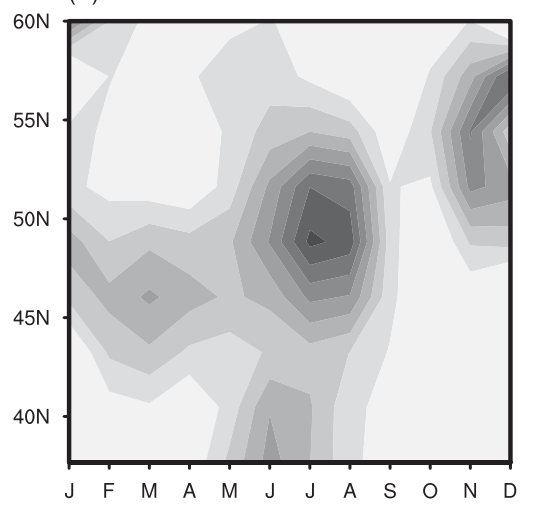

(b) Precipitation

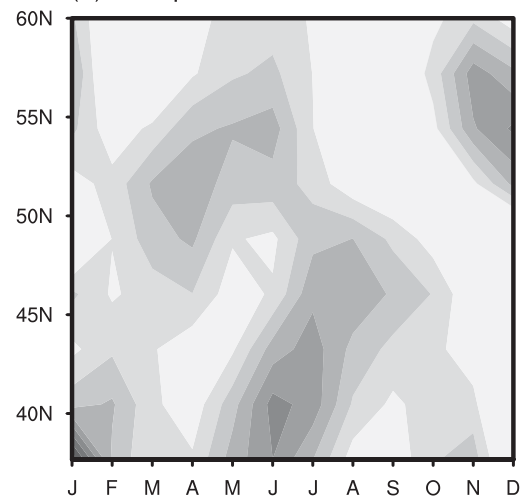

(e) Soil Moisture

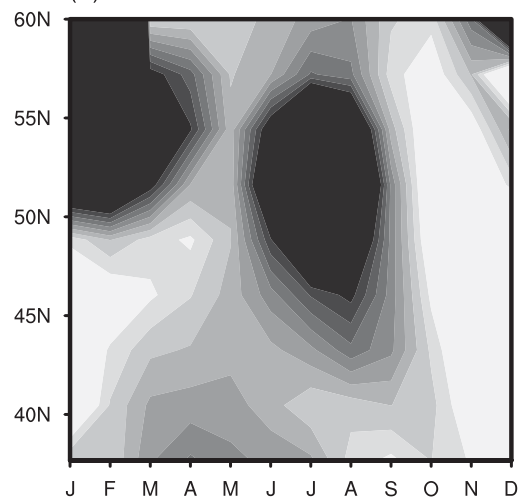

(c) Evaporation and Latent heat flux

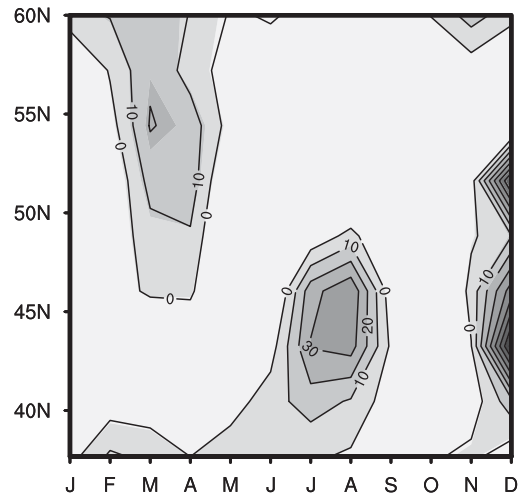

(f) Soil Temperature

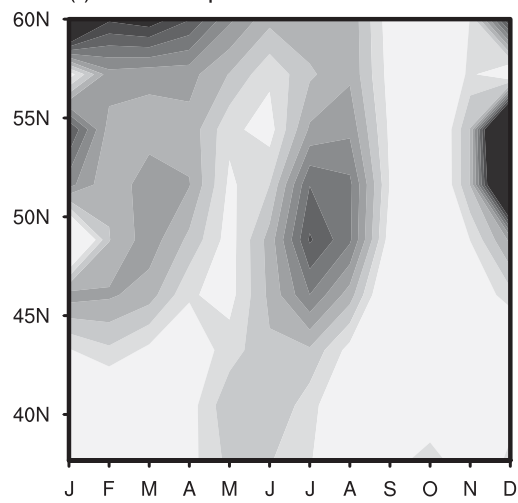

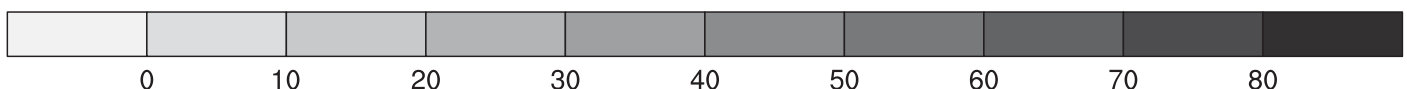

FIG. 5. Annual cycle of potential predictability (\%) of the (a) surface air temperature, (b) precipitation, (c) evaporation (shaded) and latent heat flux (contour), (d) sensible heat flux, (e) soil moisture, and (f) soil temperature in ASSIM, evaluated over Europe across $10^{\circ} \mathrm{W}-60^{\circ} \mathrm{E}$.

$35^{\circ}$ to $45^{\circ} \mathrm{N}$ from middle May to early July. Clearly, T2m obtains higher predictability than precipitation from the WCDA system in summer.

Between the land states refined by the WCDA system and the European summer temperature and precipitation, surface sensible and latent heat flux (or evaporation) play a critical role in transferring predictability signals from the land surface to the atmosphere. As Figs. 5c and 5d show, the potential predictability of sensible and latent heat fluxes is mainly concentrated during the summer in the midlatitudes. The spatiotemporal distribution of $\mathrm{T} 2 \mathrm{~m}$ predictability resembles that of sensible heat flux predictability (Figs. 5a,d). Meanwhile, sensible heat flux presents a much stronger signal of potential predictability during the summer than latent heat flux. The peak predictability of sensible heat flux exceeds $60 \%$, while that of latent heat flux is below $40 \%$ (Figs. 5c,d). It is indicated that the improved soil temperature may be the main source of potential predictability for $\mathrm{T} 2 \mathrm{~m}$, which influences $\mathrm{T} 2 \mathrm{~m}$ through its direct effect on sensible heat flux. This conclusion is highly consistent with the significant sensitivity of T2m to soil temperature (Figs. 3a-d). Similarly, the potential predictability of precipitation is primarily attributed to the ameliorated soil moisture through its linkage to latent heat flux during summer. The spatiotemporal distribution of the latent heat flux predictability closely resembles that of the precipitation predictability (Figs. 5b,c). It is still noted that latent heat flux acts as a potential link for the coupling between soil moisture and precipitation.

With the assimilation of soil moisture and soil temperature from GLDAS, the WCDA system directly contributes to the potential predictabilities of soil moisture and soil temperature. Figure 5e shows that soil moisture acquires strong signals of potential predictability. The potential predictability of soil moisture is high in the midlatitudes around $45^{\circ}-55^{\circ} \mathrm{N}$. The maximum predictability exceeds $80 \%$ for the whole summer within a broad latitude band. By comparison, soil temperature exhibits weak potential predictability, whose peak below $70 \%$ covers a very narrow band (Fig. 5f). However, soil moisture with stronger signals of potential predictability brings about a 
(a) $\mathrm{T} 2 \mathrm{~m}$

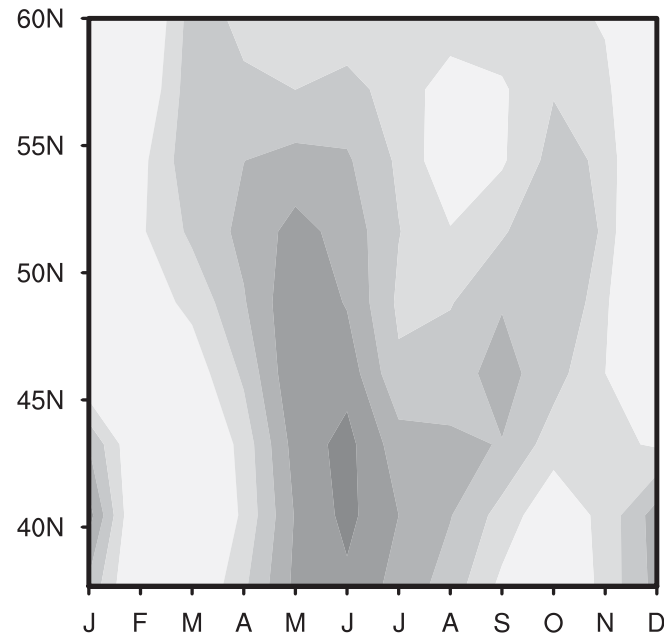

(b) Precipitation

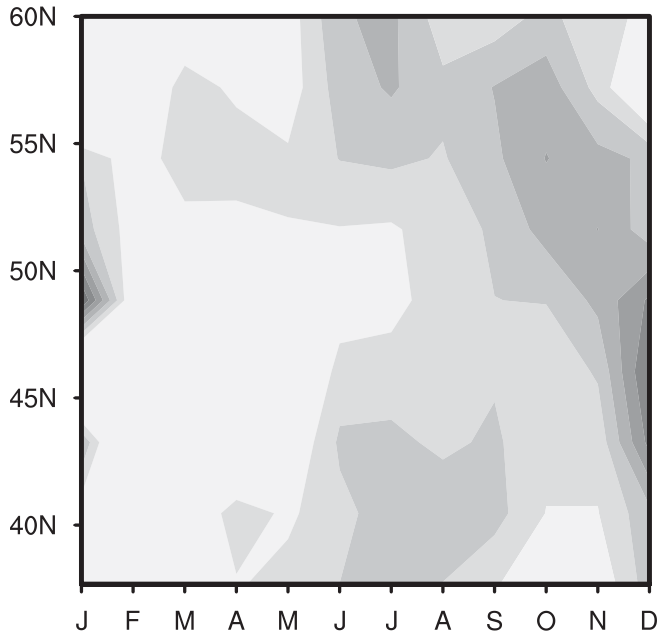

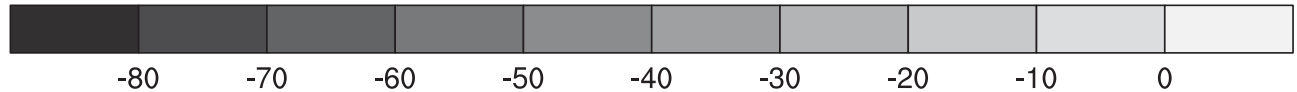

FIG. 6. Annual cycle of effective predictability (\%) of the (a) surface air temperature and (b) precipitation in HCST, evaluated over Europe across $10^{\circ} \mathrm{W}-60^{\circ} \mathrm{E}$.

lower precipitation predictability through latent heat flux, while soil temperature with weaker signals leads to a higher T2m predictability through sensible heat flux. This finding is intuitive because $\mathrm{T} 2 \mathrm{~m}$ is much more sensitive to soil temperature over the whole region of Europe, while precipitation is weakly sensitive to soil moisture only in some areas of Europe according to the results of section $4 \mathrm{~b}$. Given the importance of the land surface state in the European climate during summer, the assimilation of soil temperature and soil moisture from GLDAS can bring potential predictability to European $\mathrm{T} 2 \mathrm{~m}$ and precipitation in summer, which again suggests the possibility of improving summer climate predictions with the WCDA system.

\section{d. Effective predictability of summer climate over Europe}

Effective predictability is quite different from potential predictability. The former measures the skill score increase in initialized climate prediction from HCST, while the latter defines the variance contribution ratio of observed variability in ASSIM. In other words, potential predictability focuses on the performance of ASSIM only, while effective predictability considers the role of the initialization in the improvement of climate prediction.

The annual cycles of the zonal mean effective predictability of European climate are further analyzed (Fig. 6) according to Eq. (8). The results show that the effective predictability of $\mathrm{T} 2 \mathrm{~m}$ and precipitation in HCST is basically improved in the summer, although they are somewhat different from the results of potential predictability in terms of spatiotemporal distribution. Thus, realistic land surface initialization could enhance the effective predictability of both $\mathrm{T} 2 \mathrm{~m}$ and precipitation in the summer from HCST.
Here, the ability of HCST to reproduce the observed past climate variations, e.g., the skill score of HCST, is further quantified between the observed and predicted anomalies of summer $\mathrm{T} 2 \mathrm{~m}$ and precipitation. The focus is on the spatial pattern and time evolution of climate variability to quantify the impacts of realistic land initialization on the interannual prediction of summer $\mathrm{T} 2 \mathrm{~m}$ and precipitation.

Figures 7 and 8 show the spatial pattern of the first leading mode and the corresponding principal component (PC) of summer $\mathrm{T} 2 \mathrm{~m}$ by using EOF analysis. In the CFSR reanalysis data, the EOF pattern presents regional warming with a strong warming center over $30^{\circ}-45^{\circ} \mathrm{E}$ (Fig. 7a). Both ASSIM and HCST exhibit similar structures and warming trends in most parts of the domain (Figs. 7b,d). However, the spatial pattern in CTRL is quite different from that in the CFSR reanalysis data. The first leading EOF pattern of CTRL shows an unrealistic east-west dipole pattern, with the anomaly center moving westward and eastward (Fig. 7c). The spatial correlation of ASSIM (HCST) with the CFSR reanalysis data is 0.93 (0.89), while for CTRL, the correlation is only -0.05 . The PCs of Reanalysis, ASSIM, CTRL, and HCST are also shown in Fig. 8. The PC of the CFSR reanalysis data (Fig. 8a) depicts trends that have undergone two phases: negative (1985-94), and positive (1995-2008). Both ASSIM and HCST capture the negative trend from 1985 to 1994 and the positive trend after 1997, while CTRL fails to simulate the trends (Figs. 8b-d). The time correlation coefficient of ASSIM (HCST) with the CFSR reanalysis data is statistically significant at the $95 \%$ confidence level with $0.58(0.43)$, higher than that with CTRL (0.13).

Figures 9 and 10 display the first leading EOF patterns and the corresponding PCs of summer precipitation. From the GPCP 
(a) Reanalysis

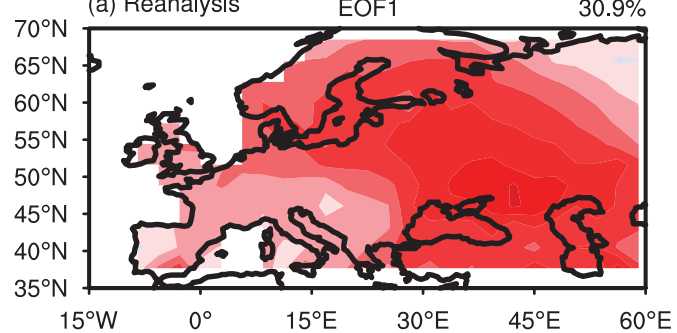

(c) CTRL

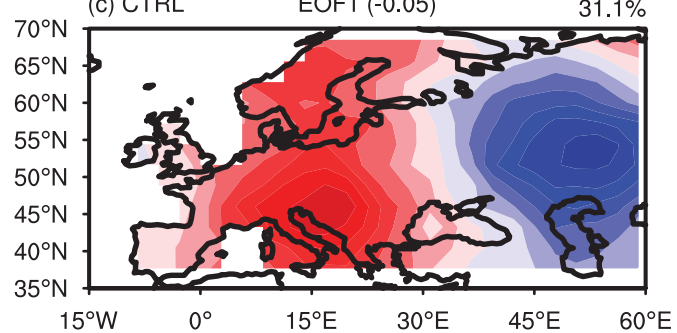

(b) ASSIM EOF1 (0.93)

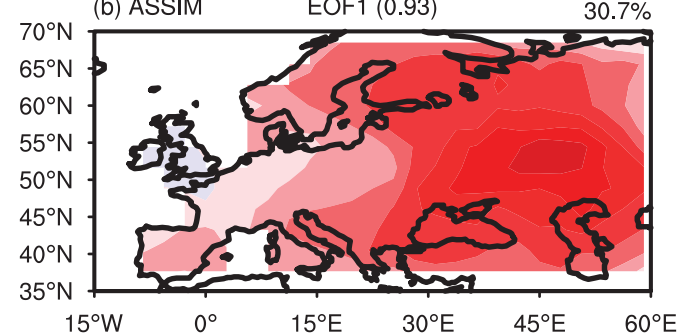

(d) HCST

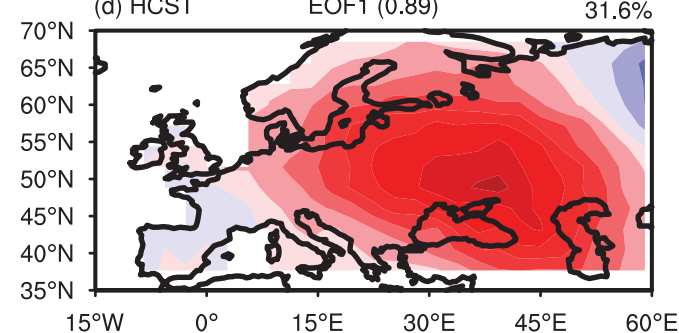

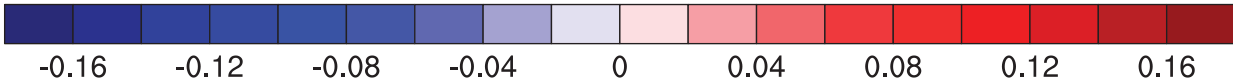

FIG. 7. The spatial pattern of the first leading mode in summer surface air temperature for 1985-2008 by the EOF analysis from (a) the CFSR reanalysis data, (b) ASSIM, (c) CTRL, and (d) HCST. The number at the top center corner of (b)-(d) is the spatial correlation with the reanalysis data. The percentage at the top right of (a)-(d) denotes the explained variance.

reanalysis data, the spatial pattern is characterized by a dipole structure with one negative pole in northern Europe and the other positive pole in southern Europe (Fig. 9a). Both ASSIM and HCST also reproduce a north-south dipole pattern (Figs. 9b,d). The large bias exists in CTRL, and the spatial pattern is quite different from the dipole pattern (Fig. 9c). The spatial correlation of ASSIM (HCST) with the GPCP reanalysis data is 0.62 (0.61), much higher than that of CTRL $(-0.44)$. The PC of
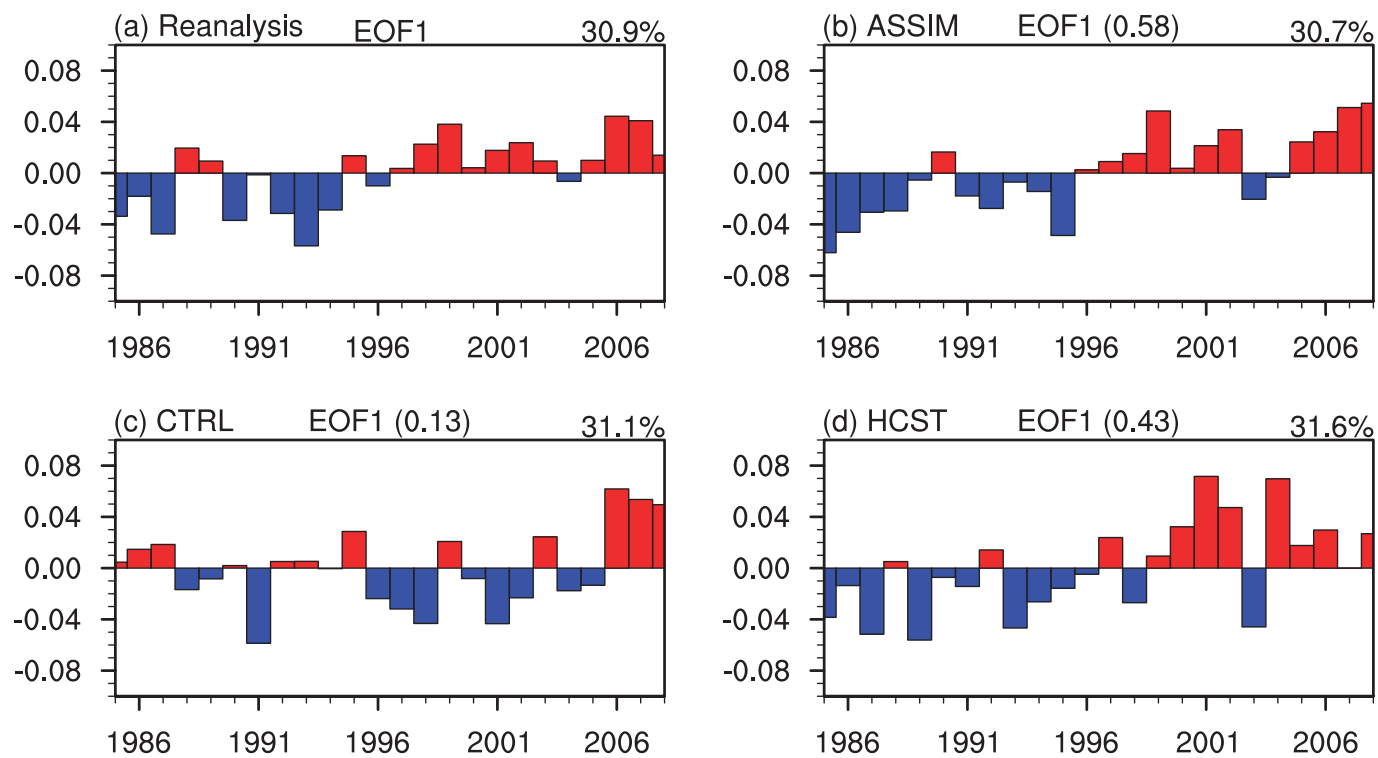

FIG. 8. The principal component of the first leading mode in summer surface air temperature for 1985-2008 by the EOF analysis from (a) the CFSR reanalysis data, (b) ASSIM, (c) CTRL, and (d) HCST. The number at the center top of (b)-(d) denotes the time correlation coefficients with the reanalysis data. The percentage at the top right of (a)-(d) denotes the explained variance. 

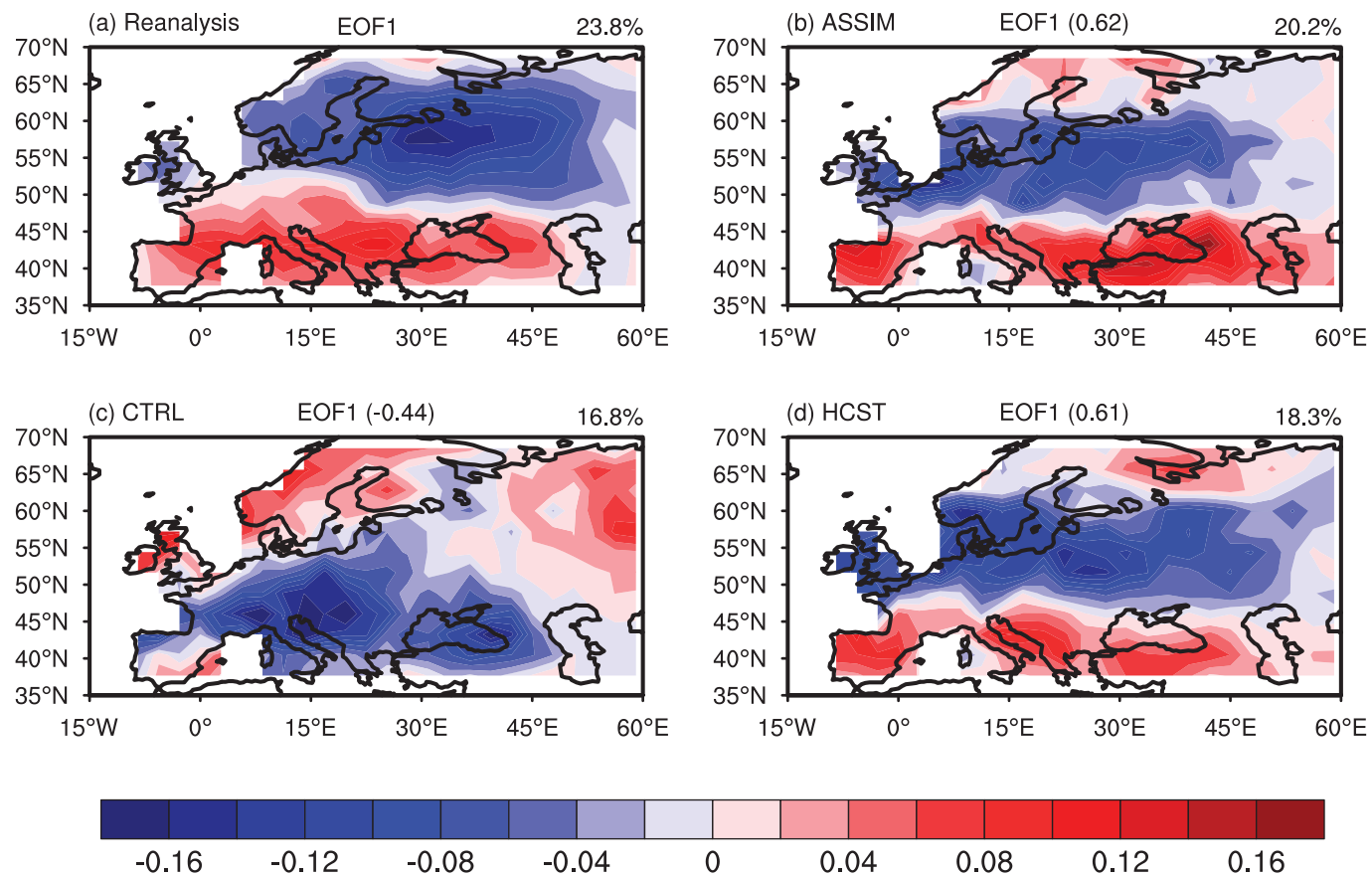

FIG. 9. The spatial pattern of the first leading mode in summer precipitation for 1985-2008 by the EOF analysis from (a) the GPCP reanalysis data, (b) ASSIM, (c) CTRL, and (d) HCST. The number at the top-center corner of (b)-(d) is the spatial correlation with the reanalysis data. The percentage at the top right of (a)-(d) denotes the explained variance.

the GPCP reanalysis data (Fig. 10a) displays the trends of three phases: negative (1985-90), positive (1991-97), and positive/negative (1998-2008). Both ASSIM and HCST capture the positive trend from 1991 to 1997 (Figs. 10b,d), while CTRL shows lowfrequency variability (Fig. 10c). The correlation coefficients of the ASSIM and HCST time series with the GPCP reanalysis (a) Reanalysis EOF1 23.8\%

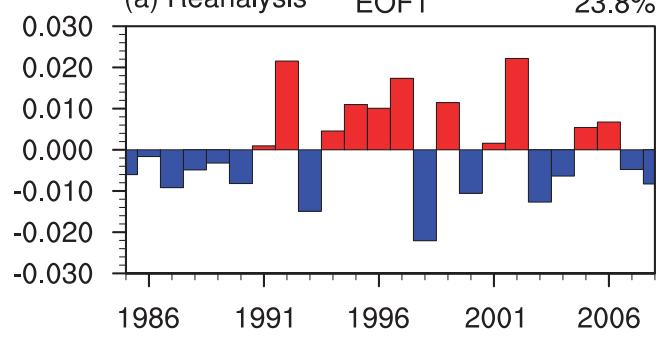

(c) CTRL EOF1 (0.04)

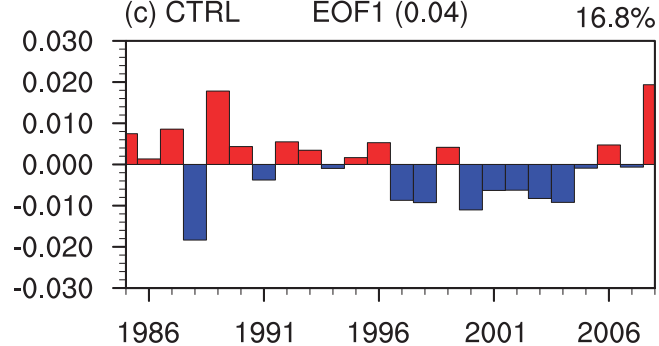

(b) ASSIM EOF1 (0.57)

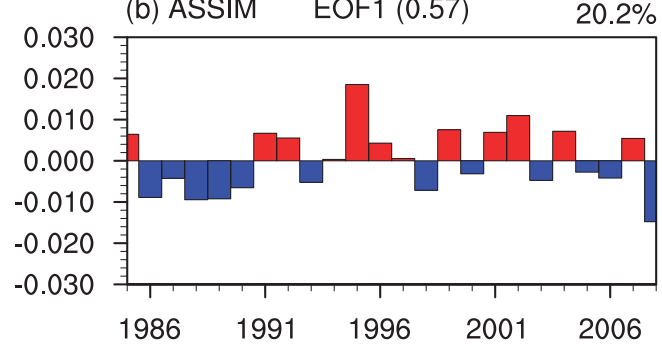

(d) HCST EOF1 (0.43)

$18.3 \%$

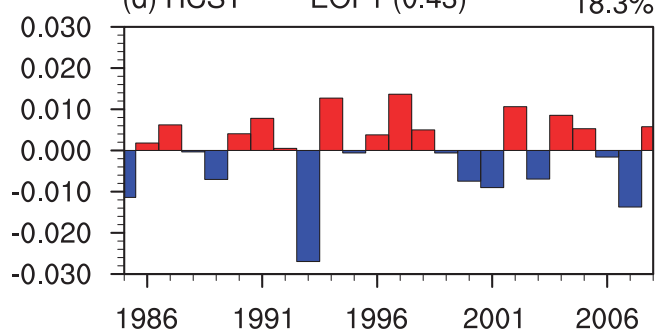

FIG. 10. The principal component of the first leading mode in summer precipitation for 1985-2008 by the EOF analysis from (a) the GPCP reanalysis data, (b) ASSIM, (c) CTRL, and (d) HCST. The number at the center top of (b)-(d) denotes the time correlation coefficients with the reanalysis data. The percentage at the top right of (a)-(d) denotes the explained variance. 


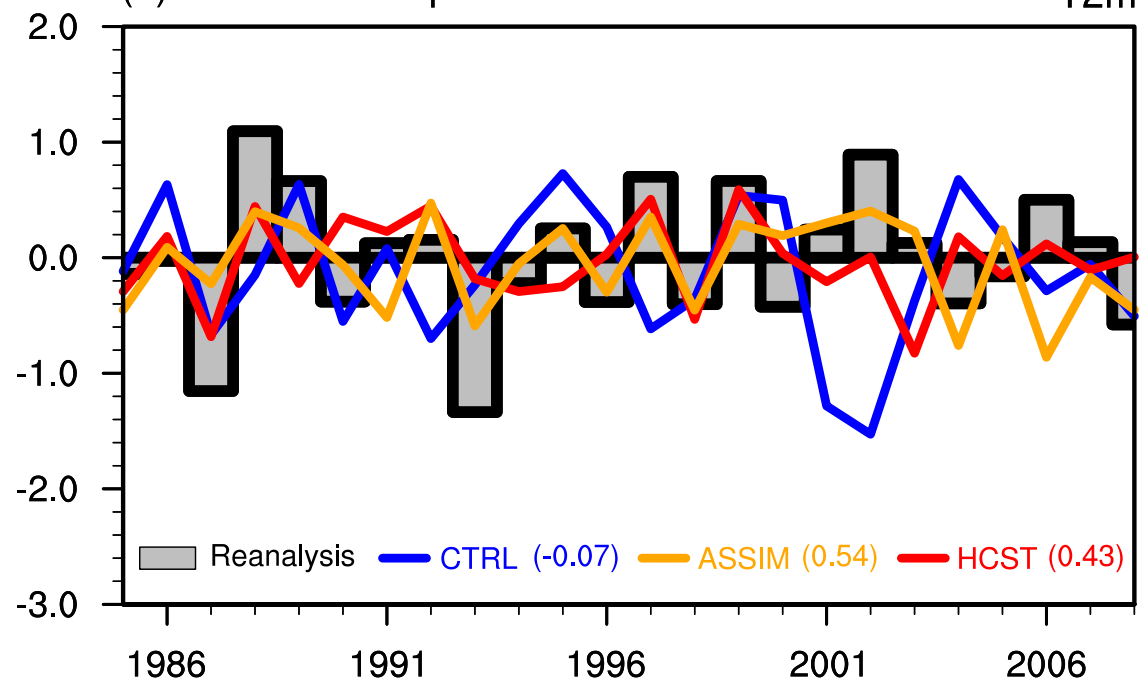

(b) Southern Europe

$\mathrm{T} 2 \mathrm{~m}$

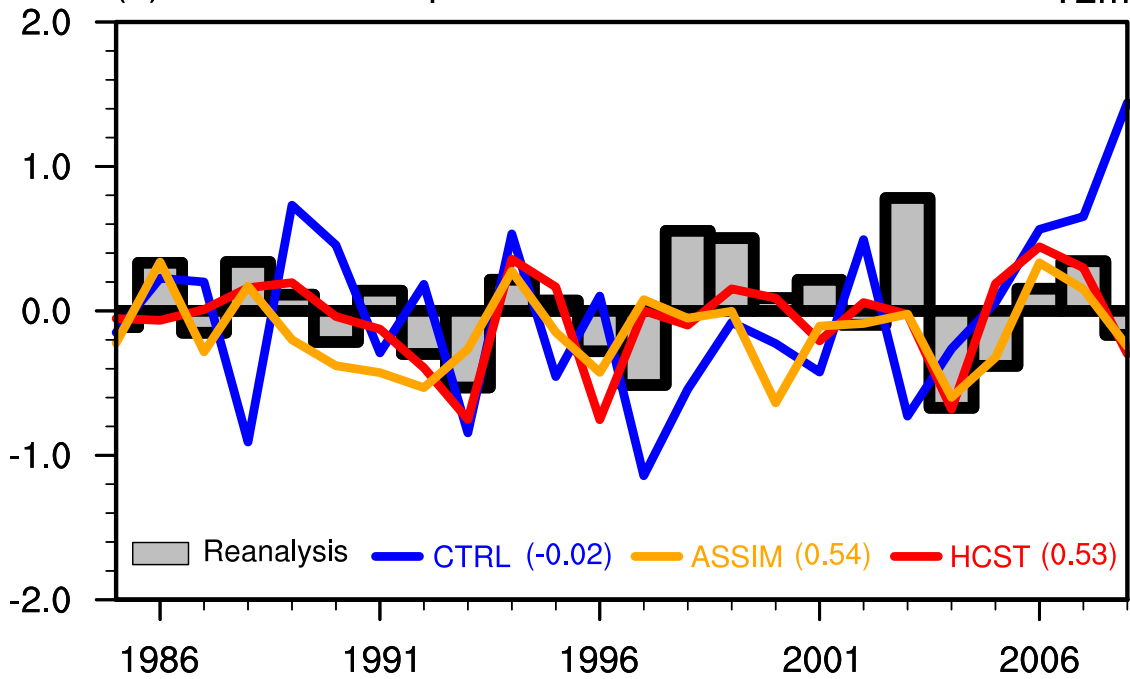

FIG. 11. The time series of summer surface air temperature anomalies in the (a) north $\left(50^{\circ}-70^{\circ} \mathrm{N}\right)$ and (b) south $\left(35^{\circ}-50^{\circ} \mathrm{N}\right)$ parts of Europe. Gray bar: CFSR reanalysis data; blue line: CTRL; orange line: ASSIM; red line: HCST. The correlation coefficients of CTRL, ASSIM, and HCST with the reanalysis data are also shown. The temperature anomalies are calculated by removing the climatology of 1985-2005 and its long-term trend.

data are statistically significant at the $95 \%$ confidence level with 0.57 and 0.43 , respectively, much higher than that of CTRL (0.04).

The time series of summer T2m anomalies in the northern and southern parts of Europe are displayed in Fig. 11. As expected, the summer prediction skill for $\mathrm{T} 2 \mathrm{~m}$ is clearly improved in HCST. HCST captures the warming anomalies from 1988 to 1992 and the phase transitions between 1987 and 1988, between 1992 and 1993, and during 1996-2000 in northern Europe, although it presents inverse anomaly phases in most of the years since 2001 (Fig. 11a). With respect to southern Europe (Fig. 11b), the magnitude of the T2m anomaly is more reasonable in HCST than that in CTRL. HCST successfully represents the observed cooling anomalies during 1990-93 and phase transitions during 1993-96. Although HCST underestimates the significant warming anomalies in 1998, 1999, and 2003, it effectively captures the prominent cooling anomalies in 1993 and 2004. The correlation coefficients of the HCST time series with the CFSR reanalysis data (north/south: 0.43/0.53) are statistically significant at the $95 \%$ confidence level, much higher than CTRL (north/south: $-0.07 /-0.02$ ). ASSIM can also capture the observed temperature anomalies well, and the correlation coefficient between ASSIM and the CFSR reanalysis data is 0.54 (0.54) for the 
(a) Northern Europe

Precipitation

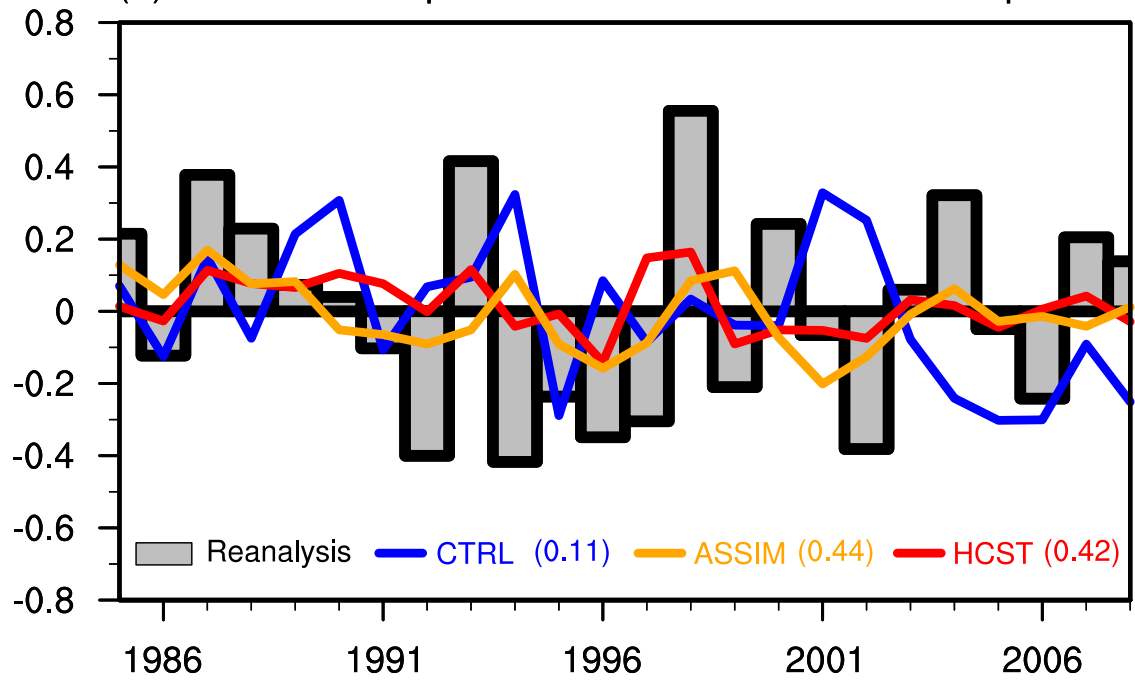

(b) Southern Europe

Precipitation

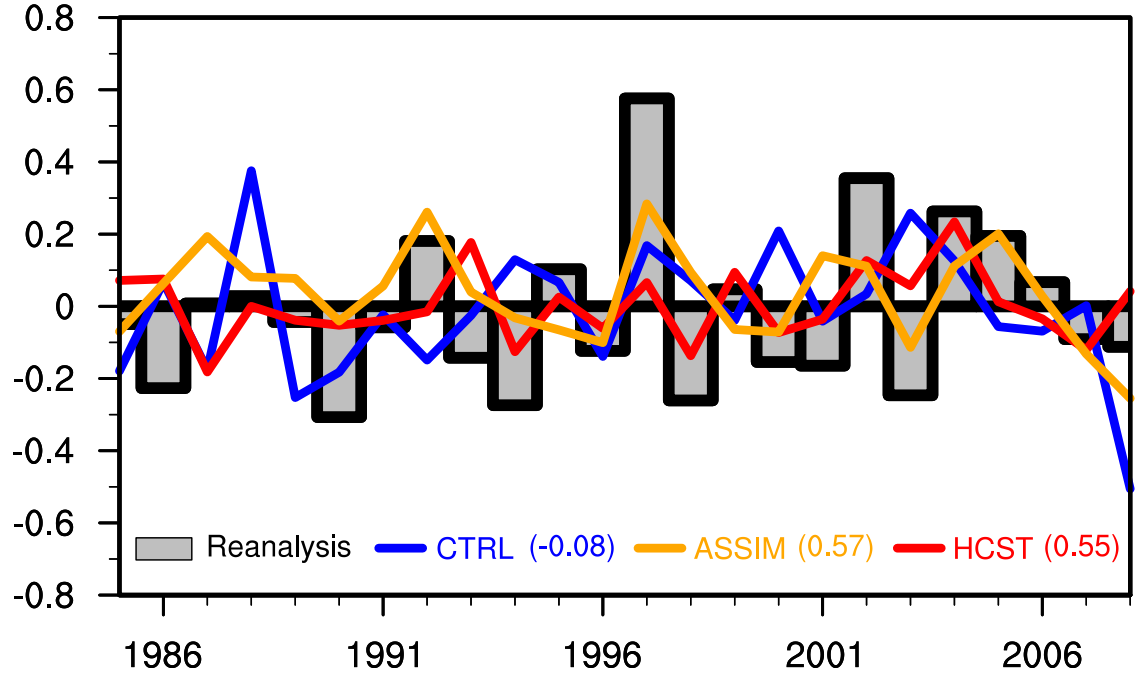

FIG. 12. The time series of summer precipitation anomalies in the (a) northern $\left(50^{\circ}-70^{\circ} \mathrm{N}\right)$ and (b) southern $\left(35^{\circ}-50^{\circ} \mathrm{N}\right)$ parts of Europe. Gray bar: GPCP reanalysis data; blue line: CTRL; orange line: ASSIM; red line: HCST. The correlation coefficients of CTRL, ASSIM, and HCST with the reanalysis data are also shown. The precipitation anomalies are calculated by removing the climatology of 1985-2005 and its long-term trend.

northern (southern) part of Europe. HCST shows significant improvements compared with CTRL, thereby emphasizing the benefit from realistic land initialization.

Then we further provide the time series of summer precipitation anomalies in the northern and southern parts of Europe (Fig. 12). Although the precipitation presented in both HCST and CTRL has a large bias in amplitude compared with the GPCP reanalysis data, HCST performs more reasonably than CTRL in phase because the correlation coefficient of HCST with the reanalysis data (north/south: 0.42/ 0.55 ) is significant at the $95 \%$ confidence level, much better than CTRL (north/south: 0.11/-0.08). The phase transitions during 1985-87, 1993-94, and 2002-05 presented by HCST well match the observed transitions in northern Europe (Fig. 12a). HCST captures 9 of 14 dry and 6 of 10 wet anomalies in the GPCP reanalysis data from 1985 to 2008 in southern Europe (Fig. 12b). Notably, the correlation coefficient is also improved in ASSIM, which highlights the importance of land boundary conditions during the summer over Europe.

Without any initialization, CTRL generally presents relatively low interannual effective predictability over Europe. The high effective predictability of HCST for summer climate 
TABLE 3. The correlation coefficients between the time series of observed and simulated anomalies of summer temperature and precipitation in HCST, CTRL, and six sensitivity experiments SNS1, SNS2, SNS3, SNS4, SNS5, and SNS6 over the north (50 $-70^{\circ}$ N) and south $\left(35^{\circ}-50^{\circ} \mathrm{N}\right)$ parts of Europe. The atmosphere, land, and ocean initial conditions for HCST and six sensitivity experiments are taken from ASSIM, CTRL, and an offline land data assimilation system (Offline).

\begin{tabular}{|c|c|c|c|c|c|c|c|}
\hline & \multirow[b]{3}{*}{ Atmosphere } & \multirow[b]{3}{*}{ Land } & \multirow[b]{3}{*}{ Ocean } & \multicolumn{4}{|c|}{ Correlation coefficient } \\
\hline & & & & \multicolumn{2}{|c|}{ Temperature } & \multicolumn{2}{|c|}{ Precipitation } \\
\hline & & & & Northern Europe & Southern Europe & Northern Europe & Southern Europe \\
\hline HCST & ASSIM & ASSIM & ASSIM & 0.43 & 0.53 & 0.42 & 0.55 \\
\hline CTRL & CTRL & CTRL & CTRL & -0.07 & -0.02 & 0.11 & -0.08 \\
\hline SNS1 & CTRL & Offline & CTRL & 0.23 & -0.15 & 0.06 & -0.01 \\
\hline SNS2 & ASSIM & ASSIM & CTRL & 0.29 & 0.17 & 0.10 & 0.18 \\
\hline SNS3 & CTRL & CTRL & ASSIM & -0.02 & 0.05 & -0.09 & 0.16 \\
\hline SNS4 & CTRL & ASSIM & ASSIM & -0.15 & 0.22 & 0.25 & 0.23 \\
\hline SNS5 & ASSIM & CTRL & CTRL & -0.17 & 0.04 & -0.19 & 0.10 \\
\hline SNS6 & CTRL & ASSIM & CTRL & 0.25 & 0.14 & 0.07 & 0.12 \\
\hline
\end{tabular}

in Europe mainly benefits from the initial states constrained by land observations. This actually suggests that realistic land initialization allows the climate model to create and maintain the actual climate fluctuations with well-presented $\mathrm{T} 2 \mathrm{~m}$ and precipitation anomalies. Simple model studies have also demonstrated that adequate land surface boundary conditions could enhance the predictability of precipitation on the interannual basis (Kanae et al. 2005).

To provide insights on the importance of well-balanced multicomponent ICs in improving the prediction skill of HCST, Table 3 summarizes the results from six sensitivity experiments. These experiments follow the basic design of HCST, except that different combinations of atmosphere, land, and ocean states from ASSIM, CTRL, and an offline LDA system are used as ICs (section 2d). Here we quantify the prediction skills using the correlation coefficients between the time series of observed and simulated anomalies of summer temperature and precipitation for comparison of the six sensitivity experiments with HCST.

Notably, the correlation coefficients of all six sensitivity experiments are significantly lower than HCST, demonstrating the important influence of LDA not only on the land states, but also on the atmosphere and ocean states during the free coupled integration in ASSIM. In SNS1, land ICs from an offline land surface model with the same LDA system used in the coupled system may result in imbalances with the atmosphere and/or ocean states from CTRL, leading to relatively low hindcast skills over the north and south parts of Europe. Initializing the ocean from CTRL instead of ASSIM in SNS2 also leads to poor hindcast performance, because the WCDA system in ASSIM could influence the ocean states to provide balanced states for the entire coupled system through multisphere interactions induced by LDA for use as ICs of HCST. In SNS3, both atmosphere and land are initialized from CTRL and the hindcast skills are still low and limited. With only atmosphere initialized based on CTRL, SNS4 demonstrates the importance of balanced atmosphere and land initial states through land-atmosphere coupling that could improve summer climate predictability. With only the atmosphere ICs initialized from ASSIM, SNS5 produces the worst hindcast over Northern Europe. This is because the atmosphere evolves quickly on a small scale, and the atmosphere can scarcely retain a long-term memory of observed information in the climate system. In SNS6, land ICs from ASSIM may achieve the additional skill and the hindcast performance is better than that of SNS5. Both the annual cycle (Fig. 1) and spatial pattern (Fig. 2) of the $K$ index highlight the important role of land surface states on the surface fluxes in the summer over Europe. The sensitivity index of summer climate to land surface states also implies that summer T2m is dominated by soil temperature (Fig. 3), and the impacts of soil moisture focus on summer precipitation (Fig. 4) over Europe. The dominant role of land surface states on summer climate also supports the significant role of realistic land initial conditions in improving interannual predictability of summer climate over Europe. Surface fluxes play a vital role in linking land surface states with the atmospheric response (Dirmeyer 2011). It is important to notice that the significant spatiotemporal correlation of potential predictability between $\mathrm{T} 2 \mathrm{~m}$ and sensible heat flux (Figs. 5a,d), as well as that between precipitation and latent heat flux (Figs. 5b,c), underscores the significant role of surface fluxes in transferring predictability signals from the land surface to the atmosphere. The impact of assimilating soil moisture and temperature can be propagated to the atmosphere through changes in the surface latent and sensible heat flux (Fig. 5). Table 4 also verifies the important role of soil moisture and temperature on the surface water balance and energy budget through their impacts on evaporation and partitioning of surface fluxes (Yoon and Leung 2015; Yang et al. 2016). This is consistent with the findings from previous studies that land impacts contribute significantly to predictability in the summer midlatitudes (Conil et al. 2007; Yang et al. 2016). With the collaboration between the land and atmosphere (ocean) ICs from ASSIM, SNS2 (SNS4) outperforms SNS6; i.e., the hindcasts are further improved. It is suggested that with the collaboration of the improved land ICs, the improved atmosphere or ocean ICs also contribute to the skill in the hindcast over Europe. The comparison between SNS2 and SNS4 indicates that the improved ocean ICs may play a more important role in the hindcast over Europe than the improved atmosphere ICs in most cases. Furthermore, the performance of HCST superior to 
TABLE 4. Multiyear mean of surface net shortwave radiation

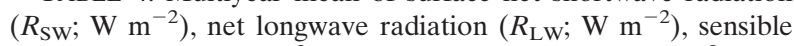
heat flux (SHF; $\mathrm{W} \mathrm{m}^{-2}$ ), latent heat flux (LHF; $\mathrm{W} \mathrm{m} \mathrm{m}^{-2}$ ), and evaporation $\left(E ; \mathrm{mm} \mathrm{day}^{-1}\right)$ for the June-August (JJA) period of 1985-2008 in ASSIM, CTRL, HCST, and CFSR Reanalysis over Europe.

\begin{tabular}{lccccc}
\hline \hline & $R_{\text {SW }}$ & $R_{\text {LW }}$ & SHF & LHF & $E$ \\
\hline ASSIM & 224.23 & 72.72 & 38.63 & 67.33 & 2.32 \\
HCST & 225.28 & 73.85 & 40.49 & 65.61 & 2.26 \\
CTRL & 227.76 & 75.31 & 42.15 & 64.07 & 2.21 \\
Reanalysis & 223.66 & 71.25 & 36.31 & 70.46 & 2.36 \\
\hline
\end{tabular}

all six sensitivity experiments highlights the importance of wellbalanced multicomponent ICs in improving the prediction skills of summer climate over the north and south parts of Europe.

\section{Conclusions and discussion}

For dynamical climate prediction systems on interannual to decadal scales based on coupled climate system models, the development of advanced assimilation techniques for providing realistic ocean ICs has been a focus of study. In contrast, land surface initialization has received less attention given the difficulty of producing reliable land surface analyses in real time. Previous studies have suggested that adequate LICs could also contribute to the improvement in boreal summer climate predictions (Dirmeyer et al. 2003; Conil et al. 2009). However, the degree to which land surface initialization can advance interannual climate prediction is still largely unexplored. Many coupled models adopt uncoupled initialization methods for land components, which directly use the results of reanalysis data such as ERA-Land (Prodhomme et al. 2016; Ardilouze et al. 2017). Unfortunately, the ICs obtained from the uncoupled methods could result in inconsistencies between their model components (Balmaseda et al. 2009). Apart from the uncoupled methods, the CDA methods apply the DA technique to one or several components of the coupled model during a long-term coupled integration. In this study, we perform the CDA with the DRP-4DVar method based on FGOALS-g2 model. The CDA method incorporates GLDAS reanalysis to the land components of FGOALS-g2 model during a coupled integration of 36 years (1980-2015); i.e., a longterm assimilation cycle is conducted under the framework of the coupled model. Therefore, initial conditions obtained from the CDA method are more consistent with the coupled model than the uncoupled initialization method, as demonstrated by some studies (Balmaseda et al. 2009; He et al. 2020b).

The WCDA system based on the DRP-4DVar method is developed to assimilate land reanalysis data into the coupled model FGOALS-g2 with the 1-month assimilation window. Different from the offline LDA system that constrains the assimilation analysis of land state variables with a standalone land surface model, this WCDA system constrains the assimilation analysis of land state variables using a coupled multisphere model that in the meantime propagates the information of land reanalysis into other components (e.g., atmosphere and ocean) through multisphere interactions, and thus benefit their initial states at the beginning of the next assimilation window. Therefore, the initialization run that consists of a 36-yr assimilation cycle with the WCDA system provides realistic LICs and well-balanced ICs of other components. Two complementary aspects of the predictability, the potential predictability (analysis of variance) and effective predictability (hindcast skill score), have been evaluated on the interannual time scale with prior knowledge of land surface conditions. The potential predictability estimates the variability forced by the land reanalysis data and its ratio over the total variability in ASSIM. The effective predictability, a measure of prediction skill, is used to quantify the impact of realistic land initialization on summer climate predictability over Europe in HCST.

The annual cycle of potential predictability reveals that the WCDA system contributes to high potential predictability mostly during the summer in the midlatitudes. It is suggested that soil temperature is the dominant contributor to T2m predictability through its impact on sensible heat flux, while soil moisture supports a significant part of precipitation predictability through its linkage to latent heat flux in the summer. Concerning effective predictability, realistic land initialization significantly improves the prediction skills of summer $\mathrm{T} 2 \mathrm{~m}$ and precipitation in HCST in terms of spatial distribution and time evolution. The prescribed realistic LICs are essential to maintain near-surface climate anomalies, as well as to be effectively predictable. Realistic land initialization appears to be an effective source of predictability for $\mathrm{T} 2 \mathrm{~m}$ and precipitation in the summer over Europe.

Herein this study shows that realistic land initialization improves the prediction of interannual summer climate variability in a coupled climate model over Europe. The comparison of different initialization techniques and different soil products could help better understand the processes involved. The best initialization strategy is still an open question, and may very well be model dependent. Deeper analysis is needed to understand the physical pathways of interactions between land, atmosphere, and ocean in the fully coupled Earth system. Given the poor skill of state-ofthe-art climate models in the summer midlatitudes (Dirmeyer 2005; Zhang et al. 2011), this study motivates the need to develop efficient real-time LDA systems under a coupled model framework, rather than offline ones, in synergy with climate prediction communities. It also motivates future work to systematically assess the contributions of land conditions to interannual climate predictions in other regions, and understand the physical pathways of land-atmosphere interactions to affect the predictability of climate variations and extreme climate events.

Acknowledgments. The first and corresponding authors acknowledge the National Natural Science Foundation of China for support through Grant 41875127. The GLDAS monthly soil moisture and soil temperature data can be downloaded from the website http://disc.sci.gsfc.85nasa.gov/ hydrology/data-holdings. The GPCP monthly precipitation data are available at https:/www.esrl.noaa.gov/psd/data/ gridded/, and the CFSR reanalysis data can be downloaded from https://hycom.org/dataserver/ncep-cfsr. 


\section{REFERENCES}

Adler, R. F., and Coauthors, 2003: The version-2 Global Precipitation Climatology Project (GPCP) monthly precipitation analysis (1979-present). J. Hydrometeor., 4, 1147-1167, https://doi. org/10.1175/1525-7541(2003)004<1147:TVGPCP $>2.0$.CO;2.

Ardilouze, C., and Coauthors, 2017: Multi-model assessment of the impact of soil moisture initialization on mid-latitude summer predictability. Climate Dyn., 49, 3959-3974, https://doi. org/10.1007/s00382-017-3555-7.

— ture on European summer climate in ensemble numerical experiments. Climate Dyn., 52, 4011-4026, https://doi.org/10. 1007/s00382-018-4358-1.

Balmaseda, M. A., and Coauthors, 2009: Ocean initialization for seasonal forecasts. Oceanography, 22 (3), 154-159, https://doi. org/10.5670/oceanog.2009.73.

Cheruy, F., J. L. Dufresne, F. Hourdin, and A. Ducharne, 2014: Role of clouds and land-atmosphere coupling in midlatitude continental summer warm biases and climate change amplification in CMIP5 simulations. Geophys. Res. Lett., 41, 64936500, https://doi.org/10.1002/2014GL061145.

Conil, S., H. Douville, and S. Tyteca, 2007: The relative influence of soil moisture and SST in climate predictability explored within ensembles of AMIP type experiments. Climate Dyn., 28, 125-145, https://doi.org/10.1007/s00382-006-0172-2.

,-- , and - , 2009: Contribution of realistic soil moisture initial conditions to boreal summer climate predictability. Climate Dyn., 32, 75-93, https://doi.org/10.1007/s00382-008-0375-9.

Craig, A., and Coauthors, 2005: CPL6: The new extensible, high performance parallel coupler for the Community Climate System Model. Int. J. High Perform. Comput. Appl., 19, 309-327, https://doi.org/10.1177/1094342005056117.

Dirmeyer, P. A., 2005: The land surface contribution to the potential predictability of boreal summer season climate. J. Hydrometeor., 6, 618-632, https://doi.org/10.1175/JHM444.1.

_ 2011: The terrestrial segment of soil moisture-climate coupling. Geophys. Res. Lett., 38, L16702, https://doi.org/10.1029/ 2011 GL048268.

— M. Fennessy, and L. Marx, 2003: Low skill in dynamical prediction of boreal summer climate: Grounds for looking beyond sea surface temperature. J. Climate, 16, 995-1002, https://doi.org/10.1175/1520-0442(2003)016<0995:LSIDPO $>2$. $0 . \mathrm{CO} ; 2$.

Douville, H., 2010: Relative contribution of soil moisture and snow mass to seasonal climate predictability: A pilot study. Climate Dyn., 34, 797-818, https://doi.org/10.1007/s00382-0080508-1.

Draper, C. S., R. H. Reichle, G. Lannoy, and Q. Liu, 2012: Assimilation of passive and active microwave soil moisture retrievals. Geophys. Res. Lett., 39, L04401, https://doi.org/10.1029/ 2011 GL050655.

He, Y., and Coauthors, 2017: Reduction of initial shock in decadal predictions using a new initialization strategy. Geophys. Res. Lett., 44, 8538-8547, https://doi.org/10.1002/2017GL074028.

— , and Coauthors, 2020a: A DRP-4DVar-based coupled data assimilation system with a simplified off-line localization technique for decadal predictions. J. Adv. Model. Earth Syst., 12, e2019MS001768, https://doi.org/10.1029/2019MS001768.

— , and Coauthors, 2020b: A new DRP-4DVar-based coupled data assimilation system for decadal predictions using a fast online localization technique. Climate Dyn., 54, 3541-3559, https://doi.org/10.1007/s00382-020-05190-w.
Hu, Y. M., Y. H. Ding, and F. Liao, 2009: An improvement on summer regional climate simulation over East China: Importance of data assimilation of soil moisture. Chin. Sci. Bull., 54, 2388-2394.

Kanae, S., Y. Hirabayashi, T. Yamada, and T. Oki, 2005: Influence of "realistic" land surface wetness on predictability of seasonal precipitation in boreal summer. J. Climate, 19, 14501460, https://doi.org/10.1175/JCLI3686.1.

Koster, R. D., and Coauthors, 2010: Contribution of land surface initialization to subseasonal forecast skill: First results from a multi-model experiment. Geophys. Res. Lett., 37, L02402, https://doi.org/10.1029/2009GL041677.

— , and Coauthors, 2011: The second phase of the Global Land-Atmosphere Coupling Experiment: Soil moisture contributions to subseasonal forecast skill. J. Hydrometeor., 12, 805-822, https://doi.org/10.1175/2011JHM1365.1.

Li, L., and Coauthors, 2013a: The Flexible Global Ocean-Atmosphere-Land System model, grid-point version 2: FGOALSg2. Adv. Atmos. Sci., 30, 543-560, https://doi.org/10.1007/ s00376-012-2140-6.

— spheric Model of IAP LASG version 2 (GAMIL2). $A d v$. Atmos. Sci., 30, 855-867, https://doi.org/10.1007/s00376-0132157-5.

Lian, T., and D. Chen, 2012: An evaluation of rotated EOF analysis and its application to tropical Pacific SST variability. $J$. Climate, 25, 5361-5373, https://doi.org/10.1175/JCLI-D-1100663.1.

Lin, L. F., A. M. Ebtehaj, J. Wang, and R. L. Bras, 2017: Soil moisture background error covariance and data assimilation in a coupled land-atmosphere model. Water Resour. Res., 53, 1309-1335, https://doi.org/10.1002/2015WR017548.

Lin, P., J. Wei, Z. Yang, Y. Zhang, and K. Zhang, 2016: Snow data assimilation-constrained land initialization improves seasonal temperature prediction. Geophys. Res. Lett., 43, 423411, https://doi.org/10.1002/2016GL070966.

Liu, D., and Coauthors, 2013: Diagnosing the strength of land-atmosphere coupling at subseasonal to seasonal time scales in Asia. J. Hydrometeor., 15, 320-339, https://doi.org/10.1175/ JHM-D-13-0104.1.

Liu, H., P. Lin, Y. Yu, and X. Zhang, 2012: The baseline evaluation of LASG/IAP Climate system Ocean Model (LICOM) version 2. J. Meteor. Res., 26, 318-329, https://doi.org/10.1007/ s13351-012-0305-y.

Liu, J., B. Wang, and Q. Xiao, 2011: An evaluation study of the DRP-4-DVar approach with the Lorenz-96 model. Tellus, 63A, 256-262, https://doi.org/10.1111/j.1600-0870.2010.00487.x.

Liu, X., and Coauthors, 2017: Impact of inconsistency between the climate model and its initial conditions on climate prediction. Climate Dyn., 49, 1061-1075, https://doi.org/10.1007/ s00382-016-3194-4.

Liu, Y. Q., 2003: Prediction of monthly-seasonal precipitation using coupled SVD patterns between soil moisture and subsequent precipitation. Geophys. Res. Lett., 30, 1827, https:// doi.org/10.1029/2003GL017709.

Mei, R., G. Wang, and H. Gu, 2013: Summer land-atmosphere coupling strength over the United States: Results from the regional climate model RegCM4-CLM3.5. J. Hydrometeor., 14, 946-962, https://doi.org/10.1175/JHM-D-12-043.1.

Oleson, K., and Coauthors, 2010: Technical description of version 4.0 of the Community Land Model (CLM). NCAR Tech. Note NCAR/TN-478+STR, 257 pp., https://doi.org/10.5065/ D6FB50WZ. 
Orsolini, Y. J., and Coauthors, 2013: Impact of snow initialization on sub-seasonal forecasts. Climate Dyn., 41, 1969-1982, https://doi.org/10.1007/s00382-013-1782-0.

Prodhomme, C., F. Doblas-Reyes, O. Bellprat, and E. Dutra, 2016: Impact of land-surface initialization on sub-seasonal to seasonal forecasts over Europe. Climate Dyn., 47, 919-935, https://doi.org/10.1007/s00382-015-2879-4.

Reichle, R. H., W. Crow, R. D. Koster, H. O. Sharif, and S. P. Mahanama, 2008: Contribution of soil moisture retrievals to land data assimilation products. Geophys. Res. Lett., 35, L01404, https://doi.org/10.1029/2007GL031986.

Rodell, M., and Coauthors, 2004: The Global Land Data Assimilation System. Bull. Amer. Meteor. Soc., 85, 381-394, https:// doi.org/10.1175/BAMS-85-3-381.

Saha, S., and Coauthors, 2010: The NCEP Climate Forecast System Reanalysis. Bull. Amer. Meteor. Soc., 91, 1015-1058, https://doi.org/10.1175/2010BAMS3001.1.

— , and Coauthors, 2014: The NCEP Climate Forecast System version 2. J. Climate, 27, 2185-2208, https://doi.org/10.1175/ JCLI-D-12-00823.1.

Sahoo, A. K., G. Lannoy, R. Reichle, and P. Houser, 2013: Assimilation and downscaling of satellite observed soil moisture over the Little River Experimental Watershed in Georgia, USA. Adv. Water Resour., 52, 19-33, https://doi.org/10.1016/j. advwatres.2012.08.007.

Santanello, J., and Coauthors, 2016: Impact of soil moisture assimilation on land surface model spinup and coupled land-atmosphere prediction. J. Hydrometeor., 17, 517-540, https:/doi. org/10.1175/JHM-D-15-0072.1.

Seneviratne, S. I., L. Daniel, L. Michael, and S. Christoph, 2006: Land-atmosphere coupling and climate change in Europe. Nature, 443, 205-209, https://doi.org/10.1038/nature05095.

Seo, E., and Coauthors, 2019: Impact of soil moisture initialization on boreal summer subseasonal forecasts: Mid-latitude surface air temperature and heat wave events. Climate Dyn., 52, 1695-1709, https://doi.org/10.1007/s00382-018-4221-4.

Shi, P., and Coauthors, 2021: Significant land contributions to interannual predictability of East Asian summer monsoon rainfall. Earth's Future, 9, e2020EF001762, https://doi.org/10. 1029/2020EF001762.

Sugiura, N., and Coauthors, 2008: Development of a four-dimensional variational coupled data assimilation system for enhanced analysis and prediction of seasonal to interannual climate variations. J. Geophys. Res., 113, C10017, https://doi. org/10.1029/2008JC004741.

Wang, B., and Coauthors, 2009: Advance and prospectus of seasonal prediction: Assessment of the APCC/CliPAS 14-model ensemble retrospective seasonal prediction (1980-2004). Climate Dyn., 33, 93-117, https://doi.org/10.1007/s00382-0080460-0.

—, and Coauthors, 2010: An economical approach to fourdimensional variational data assimilation. Adv. Atmos. Sci., 27, 715-727, https://doi.org/10.1007/s00376-009-9122-3.

— , and Coauthors, 2018: An approach to localization for ensemble-based data assimilation. PLOS ONE, 13, e0191088, https://doi.org/10.1371/journal.pone.0191088.

Wang, X., 2009: Improvements in sea ice component of IAP/ LASG climate system model. M.S. thesis, Institute of Atmospheric Physics, Chinese Academy of Sciences, $101 \mathrm{pp}$.

Wei, J., and P. A. Dirmeyer, 2012: Dissecting soil moisture-precipitation coupling. Geophys. Res. Lett., 39, L19711, https://doi. org/10.1029/2012GL053038.

Yang, K., C. Wang, and H. Bao, 2016: Contribution of soil moisture variability to summer precipitation in the Northern Hemisphere. J. Geophys. Res. Atmos., 121, 12108-12124, https://doi. org/10.1002/2016JD025644.

Yoon, J., and L. R. Leung, 2015: Assessing the relative influence of surface soil moisture and ENSO SST on precipitation predictability over the contiguous United States. Geophys. Res. Lett., 42, 5005-5013, https://doi.org/10.1002/2015GL064139.

Zhang, J., W. Wang, and L. Leung, 2008: Contribution of landatmosphere coupling to summer climate variability over the contiguous United States. J. Geophys. Res., 113, D22109, https://doi.org/10.1029/2008JD010136.

— , L. Wu, and W. Dong, 2011: Land-atmosphere coupling and summer climate variability over East Asia. J. Geophys. Res., 116, D05117, https://doi.org/10.1029/2010JD014714. 